\title{
Symposium review: Mechanistic insights into adipose tissue inflammation and oxidative stress in periparturient dairy cows*
}

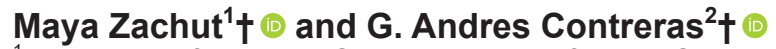 \\ ${ }^{1}$ Department of Ruminant Science, Institute of Animal Sciences, Agricultural Research Organization/Volcani Center, 7505101 Rishon LeZion, \\ Israel \\ ${ }^{2}$ Department of Large Animal Clinical Sciences, College of Veterinary Medicine, Michigan State University, East Lansing 48824
}

\begin{abstract}
During the periparturient period, lipolysis in adipose tissue (AT) mobilizes fatty acid reserves to meet high energy needs of dairy cows. This physiological response is accompanied by the synthesis and secretion of a plethora of proteins (adipokines) and lipid products that modulate metabolic functions. In the AT, lipolysis generates free radicals (FR), including reactive oxygen species, and leads to a remodeling process characterized by an inflammatory response. In the AT of healthy cows with adequate lipolytic responses, antioxidant defenses neutralize FR, and the inflammation associated with remodeling is rapidly resolved. The control of these processes is orchestrated by numerous inflammatory and oxidative stress (OS)related pathways identified by recent transcriptomic and proteomic analyses. For example, parturition and the onset of lactation enhance the transcription and translation of complement and acute-phase proteins and, at the same time, enrich antioxidant defenses that neutralize FR, including Nrf2. However, in cows with exacerbated and protracted lipolysis, the production of FR rapidly depletes antioxidant systems, and OS develops. The harmful effects of OS in AT include activating inflammatory responses and inhibiting insulin signaling within AT. By intensifying AT inflammation, OS impairs adipocyte response to insulin. This leads to a vicious circle where OS exacerbates AT lipolysis and inflammation, which further promotes OS. This review summarizes current knowledge on the mechanisms that modulate AT inflammatory responses and OS during the periparturient period of dairy cows.
\end{abstract}

Received August 31, 2021.

Accepted December 21, 2021.

*Presented as part of the Animal Health Symposium: Adipose Tissue in Transition Dairy Cows as an Integrator of Metabolic and Inflammatory Cues in Health and Disease at the ADSA Annual Meeting, July 2021.

†Corresponding authors: mayak@volcani.agri.gov.il and contre28@ msu.edu
Key words: adipose tissue inflammation, oxidative stress, free fatty acids, immune responses, lipolysis

\section{INTRODUCTION}

The adipose tissue (AT) is an energy buffer tissue that stores energy-dense fatty acids (FA) during anabolic states and releases them into circulation during catabolic conditions. The balance between lipolysis and lipogenesis determines the FA flux in and out of AT. In addition to energy buffering, the AT is an endocrine organ that modulates systemic metabolism and inflammatory processes. This function is exerted through the transcription and translation of a plethora of proteins, termed adipokines (e.g., adiponectin, fetuin-A), and lipid mediators of inflammation (e.g., oxylipins, sphingolipids). In dairy cows, the periparturient period (PP) is a catabolic state that provokes profound changes in AT function. Around parturition, hormonal changes associated with calving, lactogenesis, and reduced DMI enhance lipolysis and markedly inhibit lipogenesis (Bradford et al., 2015). Because lipolysis causes a reduction of the AT mass that may exceed $30 \%$ of the volume (i.e., weight) of adipose depots (Akter et al., 2011), it induces a remodeling process that involves inflammatory responses. In healthy cows that have limited AT lipolysis postpartum, as lactation progresses, transcriptomic and functional changes within AT enhance lipogenesis and reduce lipolysis (Zachut, 2015). In contrast, in cows with intense and protracted lipolysis induced by metabolic or inflammatory diseases, chronic inflammation in AT develops, leading to lipolysis dysregulation (Contreras et al., 2015).

The lipolytic process involves the production of free radicals (FR), including reactive oxygen (ROS) and nitrogen species. The mechanism involves the activation of FA oxidation in the mitochondria of adipocytes, which generates FR ( $\mathrm{Li}$ et al., 2005), and the peroxidation of PUFA released during lipolysis through enzymatic and nonenzymatic reactions (Cohen et al., 2011; Gartung et al., 2016). If the AT antioxidant systems do not deactivate the FR generated during lipolysis, 
oxidative stress (OS) develops, aggravating AT inflammation and lipolysis dysregulation. In fact, FR are direct activators of hormone-sensitive lipase (HSL; Zhou et al., 2019). In recent years, omics technology has provided plenty of data on AT of PP cows, and bioinformatics analyses have directed to the most prominent pathways and functions that are altered, highlighting the importance of inflammatory processes in AT. This review summarized current knowledge on the mechanisms that modulate AT inflammatory responses and OS during the PP of dairy cows.

\section{MECHANISMS OF ADIPOSE TISSUE INFLAMMATION DURING LIPOLYSIS}

Lipolysis hydrolyzes triglycerides to release free FA and glycerol. In adipocytes, lipolysis occurs via the following neutral lipase enzymes: adipose triglyceride lipase, HSL, and monoglyceride lipase. Lipase's substrates, such as triglycerides, diglycerides, and cholesterol esters, and their products, FA, are toxic to tissues (i.e., lipotoxicity) and stored within lipid droplets in adipocytes and other cells (Jarc and Petan, 2019). Lipolysis releases these toxic molecules into the cellular milieu inducing a controlled inflammatory response characterized by AT macrophage infiltration, secretion of inflammatory adipokines, extracellular matrix remodeling, and the activation of lipogenic and antioxidant pathways (Contreras et al., 2018). Together these changes, also known as AT remodeling, limit lipotoxicity and remodel the anatomical structure of the AT. Below we review different components of the inflammatory responses in AT, including macrophages and specific adipokines and lipid mediators of inflammation.

\section{Adipose Tissue Macrophages}

Macrophages, the predominant immune cell type in the AT of ruminants (Ampem et al., 2016), are a key component of the inflammatory response during lipolysis in rodents and humans (Capel et al., 2009; Lee et al., 2013). The AT macrophage (ATM) infiltration occurs during events that trigger lipolysis, such as the PP (De Koster et al., 2018; Newman et al., 2019) and feed restriction-induced negative energy balance (Contreras et al., 2016; Depreester et al., 2018). Additional evidence for ATM infiltration was recently provided by using microRNA as a biomarker of macrophage trafficking in the AT around parturition (Vailati-Riboni et al., 2017).

The ATM are broadly classified as either classical (M1), which have active proinflammatory responses, or alternative (M2), which promote inflammation resolu- tion. The ATM are made up of a mixture of M1, M2, and intermediate phenotypes. The M1 ATM secrete cytokines (such as TNF $\alpha$ and interleukins $1 \beta$ and 6 ) that mediate local and systemic inflammation and impede the antilipolytic action of insulin in adipocytes (Russo and Lumeng, 2018). The M2 phenotype is associated with healing and inflammatory resolution processes. These mononuclear cells promote the differentiation of new adipocytes (adipogenesis) that buffer excess circulating FA by re-esterification into triglycerides (Lee et al., 2016). In healthy dairy cows with moderate rates of lipolysis, M2 appear to be as abundant as M1 (Contreras et al., 2016). Healthy PP cows also show increased expression of the macrophage-related gene TREM2 (Salcedo-Tacuma et al., 2020). This gene is a marker for macrophages with an antiinflammatory phenotype that have high cholesterol metabolism and oxidative phosphorylation capacity (Willemsen and de Winther, 2020). The ATM expressing TREM2 are termed metabolically activated macrophages given their bioenergetic functions (Jaitin et al., 2019).

In cases where lipolysis is severe, such as in cows with displaced abomasum and ketosis, ATM make up $20 \%$ of the cells in the stromal vascular fraction (i.e., nonadipocytes) or $2 \%$ of the total number of cells in AT (Contreras et al., 2015). In these cows, ATM accumulate in aggregates within omental and subcutaneous depots (Contreras et al., 2015). Together, these data provide evidence supporting the determinant role of ATM in AT inflammation during PP.

\section{Protein Mediators (Adipokines) of Inflammation in AT of Dairy Cows}

The AT secretome contains proteins called adipokines and includes hormones, chemokines, cytokines and acute-phase proteins (APP). The different cellular components of AT secrete adipokines; adipocytes secrete adipokines such as leptin, several APP, and TNFo, whereas ATM secrete mainly IL6 and TNFa (Weisberg et al., 2003; Xu et al., 2003). Recently, Salcedo-Tacuma et al. (2020) performed RNaseq analysis of AT and demonstrated that the AT of multiparous PP cows enhances the transcription of several inflammation-related networks, including chemokine activity, apoptosis, lipid binding, response to LPS, and membrane rafts. Moreover, pathway analysis according to the differential genes PP showed activation of inflammatory signals (Salcedo-Tacuma et al., 2020). Transcriptomic analysis of subcutaneous AT from primiparous transition cows (Mellouk et al., 2019) also identified inflammatory genes in PP AT. In a oligonucleotide microarray analysis of subcutaneous AT from primiparous transition cows fed a control or an energy-dense diet, Minuti et al. (2020) 
reported some enrichment in inflammatory pathways in overconditioned heifers, especially those involving TNF $\alpha$ and IL1 $\beta$. These findings provide some evidence of the effect of age and parity on the inflammatory responses in AT and highlight the need for further research using advanced genome sequencing tools such as single-cell RNaseq to improve our understanding of the transcriptomic events that determine AT inflammatory responses in PP cows.

In the first proteomic analysis of $\mathrm{AT}$ in $\mathrm{PP}$ dairy cows, subcutaneous AT was considered as insulinresistant or insulin-sensitive based on the phosphorylation of protein kinase B following insulin stimulation (Zachut, 2015). In this study, one of the most relevant functions of the differentially abundant proteins in insulin-resistant AT were inflammatory response and organization of actin cytoskeleton (Zachut, 2015). Proteomic analysis of AT from cows with high versus low weight loss postpartum (reflecting lipolysis intensity) demonstrated enrichment of acute-phase signaling and complement responses, coupled with a dramatic decrease in the abundance of the OS protein glutathione reductase in AT of high weight loss cows (Zachut et al., 2018), thus linking inflammatory processes in AT to OS. In line with these findings, ketotic cows had a decrease in the abundance of LBP (LPS-binding protein) and the chemokine regakine- 1 in their AT (Xu et al., 2019). These studies support the notion that inflammation is one of the major processes in AT of PP cows, and many inflammatory proteins (including those summarized in Table 1) could participate in this response. Generally, severe AT lipolysis is accompanied by a local inflammatory response in the tissue that occurs parallel to the systemic subacute inflammation during the early postpartum period (Contreras et al., 2018). However, following the enrichment of inflammatory pathways in AT of cows treated systemically with an antiinflammatory agent (Takiya et al., 2019a), it was proposed that increased AT inflammatory responses might be related to homeostatic maintenance of circulating inflammatory signals (Bradford and Swartz, 2020), but this premise warrants further evidence. Transcriptomic and proteomic studies of AT have revealed numerous inflammatory proteins, and in the next section, we will describe the main proteins related to AT inflammation in PP dairy cows (summarized in Table 1). It is important to note that many reports cited to discuss inflammatory proteins in this review used proteomic analyses of the AT (Table 1). Therefore, the source of some of these peptides, particularly acute-phase response proteins, cannot be traced solely to the AT and could also originate from hepatic synthesis reaching the AT via the circulation. Nevertheless, proteins such as TNF $\alpha$ and ORM1 are known to be synthesized in AT.
$T N F \boldsymbol{~}$. Tumor necrosis factor- $\alpha$ was the first cytokine shown to be produced in AT and increased in conditions of obesity and adipocyte insulin resistance in mammals (Hotamisligil et al., 1993). It is a potent mediator of AT inflammation that signals through TNFR1 and TNFR2 ( $\mathrm{TNF} \alpha$ receptors 1 and 2), leading to transcriptional changes mediated through $\mathrm{NF} \kappa \mathrm{B}$ (nuclear factor- $\kappa \mathrm{B}$ ) and extracellular signal-related kinase signaling (Grant and Stephens, 2015). The ATM produce the majority of TNFo in AT (Weisberg et al., 2003), and the overall AT expression of TNF $\alpha$ increases with macrophage number (Hotamisligil et al., 1995). However, TNF $\alpha$ can also be produced by adipocytes (Hotamisligil et al., 1993), and its activity alters the metabolism of fat cells through the induction of lipolysis in many species (Grant and Stephens, 2015). In dairy cows, increased mRNA abundance of TNFA in AT was described in PP cow AT (Sadri et al., 2010; Mann et al., 2016), as well as in response to an ex vivo LPS-challenge (Mukesh et al., 2010), and its transcription was also enhanced in AT of animals calving with high BCS (Vailati-Riboni et al., 2016). Nevertheless, recent reports describe lower gene expression of TNFa in AT of early postpartum overconditioned cows when compared with cows with BCS scores of 3.0 to 3.5 (Zhang et al., 2019), whereas others did not find changes in TNFa expression in AT of cows with high versus low BCS before parturition (Alharthi et al., 2018). In postpartum cows treated with sodium salicylate, TNFA mRNA in AT tended to be lower than controls (Montgomery et al., 2019), suggesting that at least at the mRNA level, TNFA is related to the inflammatory state in AT of PP cows. However, in another study, treating postpartum cows with sodium salicylate enhanced $\mathrm{TNF} \alpha$ and complement proteins abundance in AT (Takiya et al., 2019a,b). Remarkably, continuous delivery of recombinant bovine TNFa into subcutaneous AT of lactating dairy cows showed decreased inflammatory signaling and increased IL10 protein in the contralateral AT depot (Martel et al., 2014).

The TNF $\alpha$ transcription and translation in AT can be affected by environmental temperature. For example, cows calving during summer heat load had a higher protein abundance of TNFo in AT than cows calving during the winter (Zachut et al., 2020). Notably, the production of $\mathrm{TNF} \alpha$ in cows calving during summer was exacerbated in those animals that lost more BW postpartum (Zachut et al., 2020). These findings may indicate a more robust inflammatory response in the AT of heat-stressed cows with a higher degree of lipolysis. Together, the mixed findings regarding $\mathrm{TNF} \alpha$ levels and AT inflammation imply that the proinflammatory effects of TNFa do not always lead to an increase in AT inflammatory state. The AT response is dependent on the balance and combination between anti- and 
Table 1. List of inflammatory proteins abundant in adipose tissue of peripartum cows based on proteomic analyses

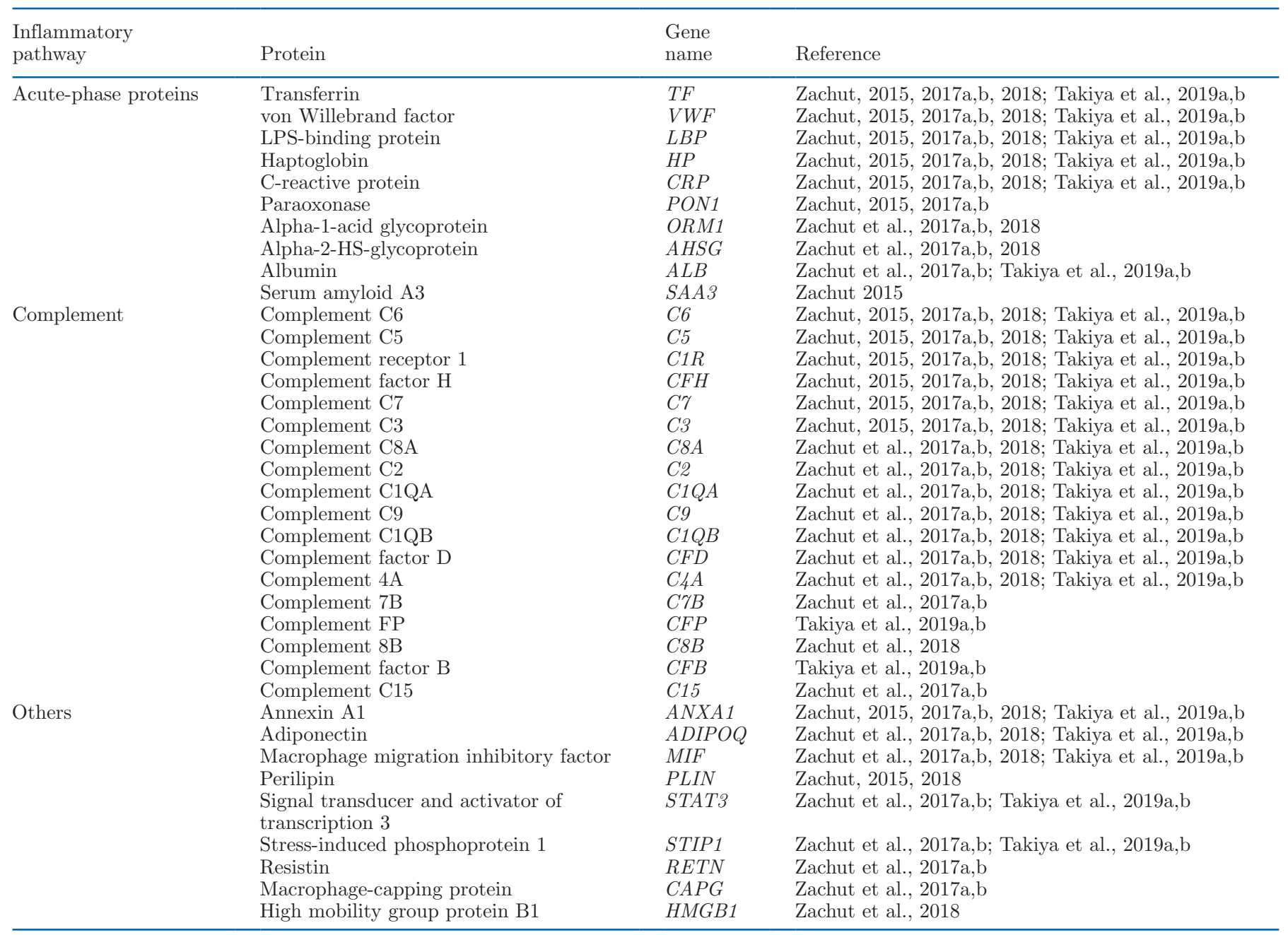

proinflammatory signals as proposed by Bradford and Swartz (2020).

IL6. Lipolysis induces IL6 (interleukin-6) secretion in rodents as an HSL activation-dependent event (Zhang et al., 2014). In dairy cows, postpartum AT IL6 upregulation is a commonly described transcriptomic finding (Depreester et al., 2018). RNaseq analyses highlight IL 6 as an upstream target for pathways involved in the recruitment and activation of phagocytes and phagocytosis (Salcedo-Tacuma et al., 2020). The intensity of BCS losses postcalving affects IL 6 expression, as demonstrated by Dirandeh et al. (2020). In their study, the mRNA abundance of genes encoding IL6, TNFA, and $I L 1 B$ in AT of dairy cows was greatest at 21 and 42 $\mathrm{d}$ postcalving in cows with a high BCS loss postpartum (Dirandeh et al., 2020). In vitro incubation of subcutaneous AT with TNFo resulted in increased expression of IL6 (Lopreiato et al., 2018); however, the expression of the cytokine was not affected by the proportion of
ATM in transition dairy cows (De Koster et al., 2018). The gene expressions of $I L 6$ are positively associated with adipocyte size; and significantly lower in subcutaneous AT than mesenteric, omental, intrapelvic, and perirenal AT (Depreester et al., 2018). To the best of our knowledge, there is a lack of evidence of IL6 in dairy cow AT at the protein level.

The 2 most well-studied adipokines that can affect AT inflammation are leptin, related to adiposity, and adiponectin, which is negatively associated with adipose mass (Grant and Stephens, 2015). In dairy cows, metabolic and endocrine effects of leptin and adiponectin were comprehensively reviewed in Sauerwein et al. (2014) and McFadden (2020); hence we will focus on their possible role in AT inflammation.

Leptin. Plasma leptin is at its nadir around parturition and reaches its peak when cows are in positive energy balance and nonlactating about $30 \mathrm{~d}$ before calving (Chilliard et al., 2005). The dynamics of plasma leptin 
and its mRNA expression in AT were described in dairy cows (Sadri et al., 2011; Zachut et al., 2018), yet its protein abundance in cows AT has not been reported. Interestingly, leptin is not detected in proteomic analyses of subcutaneous AT from PP dairy cows (Zachut, 2015; Zachut et al., 2018; Takiya et al., 2019a,b). When comparing $L E P$ gene expression in different AT depots from late-pregnant cows, LEP was higher in intrapelvic relative to subcutaneous and omental AT but was similar among the other AT sites (Depreester et al., 2018). Leptin has been shown to affect inflammation in rodents [reviewed in Brown and Bradford (2021)], yet there is scarce information on leptin and AT inflammation in dairy cows. The available data suggest a minor role in AT inflammation given its low levels of expression in subcutaneous AT of postpartum cows. However, more research is required to elucidate the role of leptin in AT inflammation in dairy cows.

Adiponectin. Adiponectin is produced almost exclusively by adipocytes. Secreted as a multimeric peptide, it can inhibit lipolysis in AT and enhance insulin sensitivity systemically (Lee and Shao, 2014). Adiponectin has antiinflammatory effects on macrophages by reducing the intensity of proinflammatory responses during pathogenic challenges (Kabara et al., 2014) and promoting the secretion of antiinflammatory cytokines in mammals (Wulster-Radcliffe et al., 2004). In AT of PP dairy cows, the protein abundance of adiponectin was demonstrated by immunoblotting (Singh et al., 2014) and proteomic analyses (Zachut et al., 2017a,b, 2018; Takiya et al., 2019a,b). Adiponectin levels in AT follow a similar pattern as their blood concentrations around parturition in dairy cows, being at their lowest immediately after calving and then increasing as lactation progresses (Sauerwein and Häußler, 2016). Blood adiponectin is inversely associated with nonesterified FA concentrations, indicating its link to lipolysis intensity in AT (Kabara et al., 2014). Comparing AT depots, the gene expression of $A D I P O Q$ is lower in subcutaneous than in intrapelvic and perirenal AT and similar to omental and mesenteric AT in late-pregnant cows (Depreester et al., 2018). In the same study, Depreester and colleagues showed that $A D I P O Q$ gene expression was not associated with the size of adipocytes, whereas the expression of inflammatory cytokines increased with cell size. It was proposed by Singh et al. (2014) that increased levels of cytokines and monocyte chemoattractant protein-1 in inflamed AT could suppress adiponectin synthesis and secretion by adipocytes. Currently, there is limited evidence on the antiinflammatory effects of adiponectin in AT inflammation in dairy cows, and additional studies are needed to evaluate its effects on AT inflammatory tone during PP.

\section{Acute-Phase Proteins}

Acute-phase proteins are highly conserved proteins that promote the systemic regulation of defense, coagulation, proteolysis, and tissue repair. The APP contribute to the resolution of inflammatory insults through their ability to sequester small molecules and regulate various innate immune functions (Ceciliani et al., 2012). The AT has emerged as a site of APP synthesis and possibly secretion. The AT APP were suggested to have a role in counterbalancing proinflammatory effects in different tissues, possibly by stimulating tissue remodeling, modulating phagocytosis, and reducing oxidative damage (Ceciliani et al., 2012). More detailed information on APP in ruminants can be found in the comprehensive review by Ceciliani et al. (2012). The following sections will discuss the latest data on the main APP in bovine AT, specifically regarding their role in AT inflammation according to proteomic data from AT in dairy cows.

Haptoglobin. The biological activities of HP include the regulation of innate immunity reactions in white blood cells, direct bacteriostatic effect, and chaperone activity (Ceciliani et al., 2012). Haptoglobin is detected at the mRNA and protein levels in visceral and subcutaneous AT from dairy cows, confirming that HP can be classified as a bovine adipokine (Saremi et al., 2012). Proteomic analysis showed that HP was significantly increased (by 64 fold) in AT of high-lipolysis versus low-lipolysis cows, as part of the enrichment of the acute-phase signaling pathway, and may indicate an increased inflammatory tone of AT in cows with a high degree of lipolysis PP (Zachut et al., 2018). Notably, the increased HP abundance in AT could also partly originate from blood; therefore, its increased abundance may be related to systemic inflammation in these cows. Based on these findings, HP is a promising marker of inflammation in bovine AT.

a-1-Acid Glycoprotein. The APP AGP ( $\alpha-1-$ acid glycoprotein), also known as ORM1, is a plasma transport protein that can modulate the inflammatory response (Ceciliani et al., 2012). Adipocytes can produce ORM1 (Sun et al., 2016), and AT expression in cattle was demonstrated by Rahman et al. (2015). In dairy cows, there is evidence for ORM1 functioning as an antiinflammatory protein that protects AT from damages related to severe inflammation (Ceciliani and Lecchi, 2019) and OS (Lykkesfeldt and Svendsen, 2007). However, in a report from Zachut et al. (2017a), ORM1 abundance was 1.7-fold lower in heat-stressed summer-calving cows, exposed to higher OS, than in winter-calving cows. The abundance of ORM1 in AT was also lower in cows with a high degree of lipolysis, 
which is related to increased OS (Zachut et al., 2018). Taken together, as ORM1 was demonstrated to have an antiinflammatory effect in AT, its reduced levels in AT of PP cows that are experiencing increased OS may promote a proinflammatory state.

Lipopolysaccharide-Binding Protein. Protein LBP binds to LPS of gram-negative bacteria and interacts with CD14, and this complex is capable of stimulating macrophages through TLR4 (toll-like receptor 4) interaction, activating a proinflammatory response (Ceciliani et al., 2012). In mice, low concentrations of LBP have a proinflammatory effect, whereas high concentrations have an antiinflammatory effect (Lamping et al., 1998). More information on the roles of LBP in inflammation appears in Ceciliani et al. (2012). In cattle, gene expression of $L B P$ is reported in different AT depots, including the subcutaneous tail head adipose (Rahman et al., 2015). Proteomic and immunoblot data suggest that the abundance of LBP in AT is increased after parturition compared with the dry period (Zachut et al., 2018). The LBP protein expression increases after oral antiinflammatory treatment with sodium salicylate during the first $7 \mathrm{~d}$ of lactation (Takiya et al., 2019a). However, immunoblot data from summer-calving cows that lost BW intensely during $\mathrm{PP}$, indicative of enhanced AT lipolysis, had lower LBP abundance in AT than cows that lost BW moderately postpartum (Zachut et al., 2020). Inflamed AT could result from ATM exposure to LPS (Newman et al., 2019); therefore, increased LBP abundance in AT could be a local response to endotoxin. It is important to note that adipocytes can serve as an intermediate storage site for LPS (Hersoug et al., 2016), implying that LPS could be released into the circulation in large quantities from the AT during intense AT lipolysis (Khiaosa-Ard and Zebeli, 2018). It was hypothesized that the decreased abundance of LBP in postpartum AT might be indicative of a decrease in LPS storage in AT, and coupled with the observed increase in LBP concentrations in plasma, this may suggest a release of LPS from the AT into the bloodstream postpartum (Zachut et al., 2020). In ketotic cows, the AT protein expression of LBP is reduced and coincides with an enriched translation of proteins related to inflammatory response pathways such as chemokine and NFkB signaling ( $\mathrm{Xu}$ et al., 2019). The lower abundance of LBP in AT of ketotic cows might have impaired the innate immune response of the AT (Xu et al., 2019). These studies suggest that lower AT LBP is related to an increase in inflammatory tone in bovine AT. Nevertheless, it is known that the release of LBP facilitates an inflammatory response to endotoxin at low concentrations; however, at high concentrations, LBP neutralizes endotoxin in lipid membranes, resulting in the reduction of TNF- $\alpha$ syn- thesis (Gutsmann et al., 2001). These findings highlight the need for additional research to elucidate the role of LBP in AT inflammation.

Fetuin-A. Fetuin-A (FetA; $\alpha-2$-Heremans-Schmid glycoprotein; encoded by the $A H S G$ gene) is an adipokine that is abundant at the mRNA and protein levels in AT of periparturient, mid-, and late-lactation dairy cows, as well as in cultured bovine adipocytes (Zachut et al., 2017a; Strieder-Barboza et al., 2018; StriederBarboza and Contreras, 2019). FetA is a negative acute-phase adipokine in the subcutaneous AT, and its plasma concentrations were negatively associated with markers of AT lipid mobilization (Strieder-Barboza et al., 2018). Proteomic analysis of AT showed that FetA abundance decreased during heat stress and was associated with increased proinflammatory and prooxidative status in late-pregnant dairy cows (Zachut et al., 2017b). In vitro, Strieder-Barboza et al. (2018) observed lower expression of MCP-1 (monocyte chemoattractant protein-1; CCL2 gene) in bovine adipocytes treated with FetA compared with LPS, indicating that FetA does not induce acute proinflammatory responses. FetA may restrain AT inflammation by modulating macrophage- and adipocyte-derived proinflammatory cytokines during PP lipolysis (Strieder-Barboza et al., 2018). Together, these studies suggest that FetA may act as a negative APP in AT and may exert antiinflammatory properties in AT of dairy cows, similar to its effects in different tissues in nonruminant species [reviewed by Wang and Sama (2012)].

Complement Proteins. The complement system is a complex network (40+ proteins) belonging primarily to the innate arm of the immune system but with the capacity to regulate adaptive responses (Ricklin et al., 2016). Complement proteins are soluble and membranebound, functioning in a cascade of stepwise proteases activation, prompting a wide spectrum of biological activities. The classical, lectin, and alternative pathways of complement system activation converge on the activation of the complement fraction $\mathrm{C} 3$, which subsequently activates $\mathrm{C} 5$ and, in a cascade, the terminal components C5 to C9. This process ultimately leads to the formation of the membrane attack complex responsible for targeting cells for lysis. Furthermore, the complement cascade produces some cleavage products, mainly C3a and C5a, with distinct local and systemic immunologic properties extending over the main lytic program (Verschoor et al., 2016). The AT represents an essential contributor to $\mathrm{C} 3$ production and systemic release (Ursini and Abenavoli, 2018). The literature on the complement system in bovine AT is scarce. At the transcriptomic level, genes encoding complement proteins C3 and C5 in AT are upregulated during the first 2 wk after parturition (Salcedo-Tacuma et al., 2020). 
Proteomic analyses of AT detected and quantified 6 to 14 complement proteins in AT from PP cows (Zachut et al., 2017b, 2018; Takiya et al., 2019b). Importantly, the complement pathway was enriched in AT at 3 time points (14 d prepartum, 4 and $30 \mathrm{~d}$ postpartum) in cows that lost BW intensely compared with cows that lost less BW postpartum (Zachut et al., 2018). Treatment of PP cows with sodium salicylate increased the abundance of $\mathrm{C} 1 \mathrm{r}, \mathrm{C} 1 \mathrm{qB}$, and $\mathrm{C} 1 \mathrm{qC}$ proteins in $\mathrm{AT}$ (Takiya et al., 2019a,b). However, it was unclear if the increase in complement protein abundance in AT was caused by macrophage AT infiltration and increased complement protein production in AT, inhibition of the complement cascade (i.e., substrate accumulation), or both (Takiya et al., 2019a). Regardless of the cellular source, the enrichment of complement pathways in AT of sodium salicylate-treated cows suggests that these proteins are involved in the inflammatory response in AT of PP cows. These findings highlight the need for more research to elucidate the role of complement in AT inflammation.

\section{Lipid Mediators of Inflammation in AT of Dairy Cows}

Lipid-derived inflammatory mediators in AT include neutral lipids (i.e., di- and monoglycerides), phospholipids (including ceramides and sphingolipids), and oxylipids. For details on the role of neutral lipids, ceramides, and sphingolipids in the modulation of inflammatory processes, the readers are referred to a comprehensive review by McFadden and Rico (2019). As for the oxylipids, these are produced from PUFA both enzymatically and nonenzymatically [extensively reviewed by Sordillo (2018)]. Oxylipid's major substrates are linoleic and arachidonic acids. Also, the omega 3 PUFA are essential substrates for antiinflammatory oxylipids such as resolvins and protectins (Sordillo, 2018). During lipolysis, PUFA are released into the cytoplasm of the adipocyte, and these lipid molecules are highly susceptible to oxidation by cyclooxygenases, lipoxygenases, and cytochrome P450 enzymes. Also, FR are capable of oxidizing PUFA in a nonenzymatic manner. Both enzymatic and nonenzymatic (FR mediated) oxidative reactions yield oxylipids that rapidly modulate inflammatory responses within AT. Remarkably, lipolysis significantly increases the content of oxylipids in the AT of healthy rodents and cows (Gartung et al., 2016; Contreras et al., 2020).

Among oxylipids generated during periparturient lipolysis, those derived from linoleic acid are of particular interest for 2 reasons. First, linoleic acid is the most abundant PUFA in bovine AT that is preferentially mobilized during the PP (Contreras et al., 2017a). Second, oxidized linoleic acid metabolites are potent modula- tors of inflammation. Similar to other PUFA, linoleic is highly susceptible to oxidation by 15-lipoxygenase and by other nonenzymatic reactions to produce hydroxyoctadecadienoic acids (HODE). Although other PUFA such as arachidonic acid are also oxidized, and their products act as proinflammatory mediators, substantial evidence supports a role for HODE as specific mediators of pro- and antiinflammatory responses in AT. The HODE act through their prooxidant action and their activation of cell membrane receptors in cells, including GPR132 (G2A) and TR4 (Obinata et al., 2005; Mahajan et al., 2012)]. For example, 13-HODE, a product of 15-lipoxygenase, promotes M2 macrophage polarization during lipolysis. In addition, 13-HODE is a potent PPAR gamma ligand that promotes adipogenesis and lipogenesis, and could reduce inflammatory responses induced during lipolysis (Lee et al., 2016). However, not all linoleic acid products help to resolve lipolysis-induced inflammation. The HODE derived from nonenzymatic oxidation such as 10-HODE and 12-HODE were recently identified as early biomarkers of lipolysis dysregulation in diabetic humans (Umeno et al., 2013). Another regioisomer, 9-HODE, promotes M1 polarization in lipid-rich environments such as atherosclerotic arteries [reviewed in Vangaveti et al. (2010)].

In periparturient cows, oxylipid concentrations in blood are dynamic and depend on lipolysis intensity. For example, 13-HODE increased 1 wk after calving from its levels 1 wk before parturition. In the meantime, plasma 9-HODE remained unchanged (Contreras et al., 2017a). When we evaluated the production of HODE in AT during the PP, we found that HSL activity is determinant in the synthesis of these oxylipids (Contreras et al., 2020). Most importantly, HSL releases linoleic acid for HODE biosynthesis in concentrations of a magnitude that may bypass the need for the activation of phospholipases linked with the inflammatory cascade, and thus supports, in part, lipolysis-driven inflammation within AT of periparturient cows.

Arachidonic acid-derived lipid mediators include eicosanoids and endocannabinoids. Prostaglandins and hydroxy-eicosatetraenoic acids are the most abundant eicosanoids in AT. The concentrations of cyclooxygenase (e.g., prostaglandins D2, E2, PGF1 $\alpha$, thromboxane, and lipoxins) and cytochrome P450 (e.g., epoxyeicosatrienoic acids) derived eicosanoids in AT remained unchanged throughout the PP of healthy cows (Contreras et al., 2017a). In contrast, the AT content of those derived from the lipoxygenase pathway (i.e., 5- and 15-hydroxyeicosatetranoic acids) and nonenzymatic oxidation (i.e., 11-hydroxyeicosatetranoic acid) increased after calving, and their concentrations were positively associated with lipolysis intensity (Contreras et al., 2017a). Higher AT concentrations of 15-hydroxyeicosa- 
tetranoic acid promote adipogenesis and reduce lipolysis (Song et al., 2016); therefore, the synthesis of this eicosanoid may be part of a feedback loop that limits the lipolytic capacity of AT after parturition.

Endocannabinoids (ECB) are also derived from arachidonic acid; the most abundant lipids of this family are anandamide, $\mathrm{N}$-arachidonoylethanolamide and 2-2-arachidonyglycerol. When these ECB bind their receptors in adipocytes, they activate adipogenesis (formation of new adipocytes) and lipogenesis [extensively reviewed by Myers et al. (2021)]. In addition, ECB have antiinflammatory activity inhibiting the expression of IL6, IL8, MCP-1 and the activation of NF-kappa $\beta$ (Silver, 2019). In dairy cows losing more than $8 \%$ of their BW postpartum, ECB in AT increased 10-fold at $4 \mathrm{~d}$ after calving compared with values at $14 \mathrm{~d}$ before parturition (Zachut et al., 2018). In contrast, cows with low BW losses did not exhibit changes in their AT ECB content. Given the antiinflammatory and antilipolytic actions of ECB, the synthesis of these lipid mediators appear to be a negative feedback loop that reduces inflammation and triglyceride catabolism in PP cows.

The inflammatory process in AT is complex and involves the activity of adipokines and lipid mediators of inflammation. The synthesis of these molecules depends on time relative to parturition, the activity of enzymes that are not directly related to inflammatory processes (e.g., HSL), and endocrine status. An additional determinant of AT inflammation is the oxidative status, which will be described in detail in the following section.

\section{MECHANISMS OF ADIPOSE TISSUE OS DURING LIPOLYSIS}

Oxidative stress is defined as an imbalance between the generation of FR, including ROS and reactive nitrogen species (RNS), and the capacity of the antioxidant systems to neutralize them. A comprehensive characterization of OS in AT is complex because it requires quantification of oxidants and antioxidants in an environment where the following occur: (1) ROS and RNS are part of redox signaling pathways that control the lipolytic process and thus increase during lipolysis, and (2) FR are products of lipolysis (McMurray et al., 2016; Abou-Rjeileh and Contreras, 2021). Currently, the OS status and the mechanisms leading to it in the AT of periparturient dairy cows are not well defined; however, different studies, summarized below, provide data on the redox signaling control of lipolysis, the sources of FR during lipolysis, and the activity of some antioxidant systems.

\section{Free Radical Production in Adipose Tissue}

All AT cellular components, including adipocytes, immune cells, endothelial cells, fibroblasts, and adipocyte progenitors, generate ROS and RNS as part of their metabolism (summarized in Table 2). The primary sources of ROS within each cell include mitochondria, peroxisomes, cytosol, cellular membrane, and the endoplasmic reticulum. The mitochondria are the major source of ROS in mammals. The mitochondrial electron transport chain generates superoxide ion $\left(\mathrm{O} 2^{\bullet-}\right)$ during respiration and $\beta$ oxidation. In monogastrics, lipolysis increases the rate of both processes (Hansen et al., 2015). In periparturient cows, negative energy balance enhances oxidative phosphorylation and mitochondrial $\beta$-oxidation in hepatocytes [reviewed by Han van der Kolk et al. (2017)]. Although this change is not demonstrated in adipocytes, the increased availability of FA for $\beta$-oxidation is likely to increase mitochondrial generation of ROS in AT. A second important source of ROS in periparturient cows AT are the peroxisomes. Their $\beta$ oxidation of FA is likely increased around parturition given the abundance of saturated and unsaturated FA released from the lipid droplet. In rodents, lipolysis increases peroxisomal activity (Xie et al., 2011). An additional critical source of ROS in periparturient cow AT is the oxidative burst in macrophages and neutrophils. During lipolysis, these cells migrate to the AT, and their inflammatory activity is enhanced in both rodents and cattle (Kosteli et al., 2010, Contreras et al., 2015).

Enzymatic and nonenzymatic lipid peroxidation and oxylipid biosynthesis are additional sources of ROS in AT. The oxylipid (i.e., oxidized FA)-synthesizing enzymes lipoxygenases and cyclooxygenases generate FR during their reactions on PUFA. For example, cyclooxygenase 2 has a peroxidase and an oxygenase component that generate ROS during its action on arachidonic acid (Yin et al., 2011). As lipolysis increases to cope with NEB postpartum, the adipocytes release abundant PUFA that are the substrates for oxylipid biosynthesis. As described in the previous section, oxylipids are synthesized in an HSL-dependent manner. Inhibiting HSL activity drastically reduces the synthesis of oxylipids and consequently the production of FR.

In AT, certain adipokines that promote inflammation can directly or indirectly enhance FR production, increasing the risk for OS (Colitti et al., 2019). TNFo promotes the generation of superoxide anions and can stimulate monocytes and macrophages to produce ROS and RNS (Fonseca-Alaniz et al., 2007). At the same time, increased ROS can enhance the release of proinflammatory cytokines and thus maintain the inflammatory processes within AT (Lavrovsky et al., 2000). 
Table 2. Free radical production in adipose tissues ${ }^{1}$

\begin{tabular}{|c|c|c|c|}
\hline Source & Major biochemical reactions (enzyme) & $\begin{array}{l}\text { Free radicals } \\
\text { produced }\end{array}$ & Reference \\
\hline Cytosol & $\begin{array}{l}\text { - Hypoxanthine } \rightarrow \text { Xanthine (xanthine oxidase) } \\
\text { - } \mathrm{O}_{2} \rightarrow \mathrm{O}_{2}{ }^{--} \text {(NOX4) } \\
\text { - Protein folding } \\
\text { - Fatty acid desaturation (stearoyl-CoA } \\
\text { desaturase- } 1 \text {, cytochrome b5) }\end{array}$ & $\begin{array}{l}\mathrm{O}_{2}^{\bullet-}, \mathrm{H}_{2} \mathrm{O}_{2} \\
\mathrm{O}_{2}^{\bullet-}, \mathrm{H}_{2} \mathrm{O}_{2}\end{array}$ & $\begin{array}{l}\text { Kelley et al., } 2010 \\
\text { Den Hartigh et al., } 2017 \\
\text { Jedrychowski et al., } 2015 \\
\text { Napier et al., } 2003\end{array}$ \\
\hline Mitochondria & $\begin{array}{l}\text { - Mitochondrial electron transport chain } \\
\text { (complex I and III, superoxide dismutase) } \\
\text { - Fatty acid oxidation }\end{array}$ & $\mathrm{O}_{2}^{\bullet-}, \mathrm{H}_{2} \mathrm{O}_{2}$ & Murphy, 2009 \\
\hline Peroxisomes & - Fatty acid oxidation (peroxisomal oxidases) & $\mathrm{O}_{2}^{\bullet-}, \mathrm{H}_{2} \mathrm{O}_{2}$ & Liu et al., 2019 \\
\hline $\begin{array}{l}\text { Respiratory burst in macrophages } \\
\text { and polymorphonuclear cells }\end{array}$ & $\bullet \mathrm{O}_{2} \rightarrow \mathrm{O}_{2}^{\bullet-}$ (NOX enzymes) & $\mathrm{O}_{2}^{\bullet--}, \mathrm{H}_{2} \mathrm{O}_{2}$ & Tan et al., 2016 \\
\hline Cellular membrane & - Lipid peroxidation (phospholipase A) & $\mathrm{O}_{2}^{\bullet-}, \mathrm{H}_{2} \mathrm{O}_{2},{ }^{\bullet} \mathrm{OH}$ & Duncan et al., 2008 \\
\hline
\end{tabular}

${ }^{1} \mathrm{H}_{2} \mathrm{O}_{2}=$ hydrogen peroxide; $\mathrm{O}_{2}{ }^{\bullet-}=$ superoxide anion; ${ }^{\bullet} \mathrm{OH}=$ hydroxyl radical.

As for the generation of RNS in bovine AT, data are scarce. In mice and humans, the main source of the most abundant RNS, nitric oxide and peroxynitrite, in AT are the endothelial and inducible nitric oxide synthases (Ribiere et al., 1996).

\section{Redox Signaling Control of AT Metabolic Functions}

The major metabolic functions of adipose depots such as lipolysis, lipogenesis, adipogenesis (development of new adipocytes), and adipokine biosynthesis are dependent on redox signaling (summarized in Table 3). Redox signaling is defined as when a biological system changes its function in response to alterations in the concentrations of ROS and RNS (Collins et al., 2012). The ROS such as $\mathrm{O}_{2}^{\bullet-}$, hydrogen peroxide $\left(\mathrm{H}_{2} \mathrm{O}_{2}\right)$, and peroxyl radical $\left(\mathrm{OH}^{\bullet}\right)$, have pro- and antilipolytic effects depending on their concentration. Similar findings indicate that RNS nitric oxide (NO) and peroxynitrite $\left(\mathrm{ONOO}^{-}\right)$also have modulatory effects on AT lipid mobilization.

Lipolysis. During the PP, lipolysis is induced through the classic and inflammatory pathways ( $\mathrm{Zu}$ et al., 2009; Arner and Langin, 2014). The classic pathway is initiated by signaling through $\beta$-adrenergic, growth hormone, and natriuretic peptide receptors. These activate adenylyl or guanylyl cyclases that increase the production of cAMP and cGMP, which are second messengers that turn on protein kinases $\mathrm{A}$ and G. Both kinases phosphorylate HSL, PLIN1, adipose triglyceride lipase, and its coactivator CGI-58, leading to triglyceride hydrolysis (i.e., lipolysis). In the inflammatory pathway, signaling molecules such as toll-like receptors, IL6, and TNF $\alpha$ activate PKC (protein kinase C) and indirectly PKA (protein kinase A), leading to the activation of lipolysis. Redox signaling can modulate different components of both lipolytic pathways.

At the cellular membrane receptor level, the ROS $\mathrm{O}_{2}{ }^{\bullet-}$ and $\mathrm{H}_{2} \mathrm{O}_{2}$ oxidize the $\beta$-adrenergic receptor and increase their sensitivity to adrenaline and other vasoactive amines, thus enhancing lipolysis (Rambacher and Moniri, 2020). The binding of growth hormone to its receptor, a major trigger of lipolysis in periparturient cows, in adipocytes increases the production of $\mathrm{H}_{2} \mathrm{O}_{2}$ and indirectly activates the $\beta$-adrenergic receptor. The ROS also act as second messengers that modulate the activation of protein kinases (e.g., PKA and PKC) that ultimately phosphorylate the lipase HSL. The ROS inhibit cAMP-dependent PKA at high concentrations, but at low concentrations, these prolong the activation

Table 3. Free radical control of adipose tissue function ${ }^{1}$

\begin{tabular}{|c|c|c|c|}
\hline Process & $\begin{array}{l}\text { Free } \\
\text { radical }\end{array}$ & Effect & Reference \\
\hline Adipogenesis & $\begin{array}{l}\mathrm{H}_{2} \mathrm{O}_{2} \\
\mathrm{H}_{2} \mathrm{O}_{2}\end{array}$ & $\begin{array}{l}\text { - Enhance adipose stem cell commitment to become adipocytes } \\
\text { - Activation of fatty acid synthase } \\
\text { - Enhance expression of perilipin } 1\end{array}$ & $\begin{array}{l}\text { Higuchi et al., } 2013 \\
\text { Abd Eldaim et al., } 2010 \\
\text { Müller et al., 2008 }\end{array}$ \\
\hline Lipolysis & $\mathrm{O}_{2}^{\bullet-}, \mathrm{H}_{2} \mathrm{O}_{2}$ & $\begin{array}{l}\text { - Oxidation of } \beta \text {-adrenergic receptors } \\
\text { - } \mathrm{H}_{2} \mathrm{O}_{2} \text { is the signaling mechanism of growth hormone to activate } \\
\beta \text {-adrenergic receptors } \\
\text { - Low concentration of } \mathrm{O}_{2}{ }^{--} \text {and } \mathrm{H}_{2} \mathrm{O}_{2} \text { activate protein kinases (A } \\
\text { and C) } \\
\text { - Direct phosphorvlation of hormone-sensitive lipase }\end{array}$ & $\begin{array}{l}\text { Rambacher and Moniri, } 2020 \\
\text { DeYulia et al., } 2005 \\
\text { Humphries et al., } 2002 \\
\text { Zhou et al., } 2019\end{array}$ \\
\hline
\end{tabular}

${ }^{1} \mathrm{H}_{2} \mathrm{O}_{2}=$ hydrogen peroxide; $\mathrm{O}_{2}{ }^{--}=$superoxide anion; ${ }^{\bullet} \mathrm{OH}=$ hydroxyl radical. 
of PKA by inhibiting the phosphatase that suppresses it. As for PKC, at high concentration, $\mathrm{O}_{2}{ }^{\bullet-}$ and $\mathrm{H}_{2} \mathrm{O}_{2}$ activate it through the release of diacylglycerol or may inactivate it by impairing its substrate-binding affinity. At low concentrations, ROS activate PKC by oxidizing its structural cysteine residues. $\mathrm{H}_{2} \mathrm{O}_{2}$ activates $\mathrm{PKC}$ by increasing $\mathrm{Ca}^{2+}$ concentrations. Both $\mathrm{O}_{2}{ }^{--}$and $\mathrm{H}_{2} \mathrm{O}_{2}$ increase lipolysis by inducing the phosphorylation of HSL directly (Zhou et al., 2019); therefore, during times of OS, it is expected that the lipolytic activity of this neutral lipase is enhanced.

Adipogenesis. Adipogenisis is the differentiation of adipocyte progenitor cells into adipocytes. This process is important in PP dairy cows because increasing adipocyte populations augments the capacity of AT to store excess nonesterified FA. The ROS generated by NOX4 (NADPH oxidase 4) and mitochondria promote adipogenesis. NOX4-derived $\mathrm{H}_{2} \mathrm{O}_{2}$ is necessary for the commitment of human adipocyte progenitor cells to become adipocytes (Schröder et al., 2009; Higuchi et al., 2013). The activation of NOX4 is triggered by insulin and is one of the critical mechanisms by which the pancreatic peptide promotes adipogenesis (Schröder et al., 2009). The ROS generated in the mitochondria complex III are also necessary for the process of adipogenesis as targeting antioxidants to this organelle inhibits adipocyte differentiation (Tormos et al., 2011). The mechanism of action of mitochondrial and NOX4 ROS for triggering adipogenesis is by activating the transcription of $\mathrm{C} / \mathrm{EBP} \alpha(\mathrm{CCAAT} /$ enhancer-binding protein $\alpha)$ and PPAR $\gamma 2$ (peroxisome proliferator-activated receptor gamma 2) (Tormos et al., 2011). Both transcription factors are determinants in the commitment of progenitors to the adipogenic fate. Less is known about the effects of RNS on adipogenesis. Because excessive levels of ROS impair the adipogenic process, the activation of antioxidant enzymes is also essential for efficient adipocyte progenitor differentiation (Krautbauer et al., 2014). During adipogenesis, antioxidant enzymes are regulated by transcription factors such as FOXO1 and Nrf2 (Higuchi et al., 2013). A reduction in the activity of the glutathione system during the adipogenesis process is necessary for its efficiency as increasing glutathione (GSH) content dramatically reduces the capacity of adipocyte progenitor cells to transform into adipocytes (Vigilanza et al., 2011).

Lipogenesis. Although lipogenesis is drastically reduced during the $\mathrm{PP}$, it is not completely shut down and is part of the AT remodeling process (Contreras et al., 2017b). De novo lipogenesis and the synthesis of triglycerides are essential for storing energy as triglycerides in adipocyte's lipid droplets. In line with $\mathrm{H}_{2} \mathrm{O}_{2}$ proadipogenic effects, this ROS also promotes lipogenesis at low $(0.15-0.5 \mathrm{mM})$ concentrations (May and de Haën, 1979). The mechanism of action is by enhancing the transcription of FA synthase in a SREBP (sterol regulatory element-binding protein)-1 dependent manner (Abd Eldaim et al., 2010). Fatty acid synthase activity is increased in the presence of normal physiological levels of NO (Choi et al., 2016). The ROS also regulates the synthesis of glycerol, the backbone of triglycerides. $\mathrm{H}_{2} \mathrm{O}_{2}$ at normal physiological levels enhances pyruvate dehydrogenase kinase- 4 activity (Townsend et al., 2020). $\mathrm{H}_{2} \mathrm{O}_{2}$ also promotes the expression of perilipin 1 and thus the formation of lipid droplets that contain triglycerides (Müller et al., 2008). In contrast to ROS, nitric oxide appears to inhibit lipogenesis and the formation of lipid droplets (Yang et al., 2018).

\section{Antioxidant Pathways in AT}

Periparturient lipolysis activates several antioxidant pathways in the AT in what appears to be an adaptive response to the intense production of ROS and RNS. To neutralize FR, the AT activates antioxidant defenses, including the GSH, SOD (superoxide dismutase), and the Nrf2 systems, and mitochondrial uncoupling. During negative energy balance, the energy sensor AMPK increases its activity triggering the activation of antioxidant pathways (Hardie et al., 2012). In bovine adipocytes, Xu et al. (2021) demonstrated that AMPK activation increases the antioxidant response by enhancing Nrf2 response through its key component Nrf2 (also known as NFE2L2) and its downstream targets HMOX1 (heme oxygenase 1), SOD1, CAT (catalase), and GST (glutathione-S-transferase).

Antioxidant activity may be affected by adiposity. Remarkably, cows with high BCS, which usually have higher periparturient lipolysis levels in AT, exhibit a more robust antioxidant response in AT. Liang and colleagues (Liang et al., 2020) showed that the abundance of NFE2L2 in AT was higher in cows with high BCS versus those with normal adiposity. However, the level of activity of Nrf2 was lower in overconditoned cows, suggesting a decrease in the activity of this antioxidant system. Notably, the abundance of GSH metabolismrelated genes GSR (glutathione reductase), GPX1 (glutathione peroxidase 1), and TALDO1 (transaldolase 1), along with protein abundance of GSTM1 (glutathione S-transferase mu 1), was greater in high-BCS cows (Liang et al., 2020). Liang et al. (2019) showed that the transcription of genes encoding different system components, including GSTM1, GSTA4, GPX1, and $G P X$ increases during the first weeks after calving. This enhanced transcription is reflected in the higher con- 
tent of these proteins. Although these authors did not measure the activity of the glutathione system in AT directly, it is expected that cows with robust responses of this system have lower OS.

In PP cows with intense and protracted lipolysis during the first month of lactation, the production of FR rapidly depletes antioxidant systems, and OS develops (Mavangira and Sordillo, 2018). The effects of OS in AT are harmful and include the activation of inflammatory responses and the inhibition of insulin signaling. The FR damages AT cellular components, including phospholipid membranes and peptides, promotes the activation of inflammatory pathways (e.g., NFkB), and enhances the expression of chemotactic cytokines that recruit macrophages (Sordillo, 2018). It is relevant to the AT that FR oxidize FA released from triglycerides during lipolysis, producing oxylipins (Gartung et al., 2016). Among these, oxidized linoleic acid metabolites such as 9- and 12-HODE are abundantly produced during OS and induce a proinflammatory polarization of macrophages (Contreras et al., 2020). By intensifying AT inflammation, OS impairs adipocyte responses to insulin, leading to a vicious circle where OS exacerbates AT lipolysis and inflammation, which further promotes OS (Contreras et al., 2017b). To prevent periparturient OS in AT, it is necessary to enhance the antioxidant defenses in AT, especially in cows that are more susceptible to excessive lipolysis such as those with high BCS, and during metabolic diseases such as clinical hyperketonemia and hypocalcemia. However, our current knowledge of AT antioxidant function and its responses to antioxidant supplementation is limited and should be the focus of future research.

\section{Protein Indicators of Oxidative Stress in Adipose Tissue}

The enzyme SOD catalyzes an antioxidant mechanism that decreases concentration FR and maintains good antioxidant capacity in tissues (Sordillo and Aitken, 2009). When cows were retrospectively divided by BCS before parturition, increased gene expression of SOD1 and the mitochondrial enzyme SOD2 was found at 7-d postpartum in AT of cows that were with low-BCS compared with high-BCS cows. The greater expression of SOD1 in low-BCS cows could have helped the AT maintain a proper antioxidant status (Alharthi et al., 2018). In overconditioned animals, the rapid expansion of AT and adipocyte sizes leads to increased intercapillary distance, resulting in decreased blood flow and reduced oxygen supply that might cause local hypoxia (Cao, 2013). In response to hypoxia, AT produces HIF$1 \alpha$ (hypoxia-inducible-factor- $1 \alpha$ ), a transcription factor that can lead to inflammation and cell death in AT (Yin et al., 2009). In a study that provided nonpregnant, nonlactating cows with a ration of increasing energy density for $15 \mathrm{wk}$, to increase BW and body condition, the number of HIF- $1 \alpha-$ positive cells in AT increased 3.3-fold from wk 0 to 15 , and HIF-1 $\alpha$ protein levels increased 2.6-fold from wk 0 to 8 (Laubenthal et al., 2017).

Proteomic analyses of AT from cows calving in summer during heat load showed enrichment of Nrf2-OS and acute-phase signaling responses when compared with AT of winter-calving cows (Zachut et al., 2017b). Summer-calving cows also showed a higher abundance of STIP1 (stress-induced phosphoprotein-1) and von Willebrand factor, and a lower abundance of OS proteins such as GSTM1 and GSTM3. In addition, when examining the AT of postpartum cows calving during summer that varied in the degree of AT lipolysis, an increase in $\mathrm{TNF} \alpha$ and a decrease in LBP was apparent compared with cows with a low degree of AT lipolysis (Zachut et al., 2020). Together, these studies support the concept that AT lipolysis, OS, and inflammation are related processes, and different conditions such as the degree of fatness, AT lipolysis intensity, and external stressors such as heat load can influence the dynamics of these processes in the AT of periparturient dairy cows. In the following section, we will describe proteins related to the Nrf-2 OS response, which is one of the most important pathways related to OS in AT of dairy cows. The levels of antioxidants and antioxidant enzymes such as GSH and GSH peroxidases are also related to OS response and will be discussed.

\section{Nrf2-Oxidative Stress Response in AT}

Nuclear factor erythroid 2-like 2 is a key transcription factor controlling cellular OS in part by increasing the mRNA abundance of antioxidant enzymes (Kaspar et al., 2009). The role of Nrf2 and OS in AT development and function is complex and depends on many factors, such as the various sources of OS, the temporal aspects of Nrf2 expression in AT differentiation, and the age and genetic background of the animal (Schneider and Chan, 2013). More information on the mechanisms related to the Nrf2 OS response can be found in a comprehensive review by Schneider and Chan (2013).

In dairy cows, proteomic analysis of AT from latepregnant cows during summer and winter highlighted Nrf2-mediated OS response as one of the most enriched pathways. Importantly, the abundance of 7 differentially expressed proteins related to Nrf2-mediated OS response was altered in the AT from cows that calved during the summer months. Among these, the abun- 
dance of STIP1 and UBE2K (ubiquitin-conjugating enzyme E2 K) were increased. In contrast, the contents of GSTM1, MGST1 (microsomal GST 1), GSTM3, FTH1 (ferritin heavy chain), and MAP2K1 (mitogenactivated protein kinase 1) were decreased (Zachut et al., 2017b). Nutritional status can also alter Nrf2 activity. Methionine supplementation during the PP reduced the abundance of the Nrf2 protein in AT at $10 \mathrm{~d}$ postpartum compared with control cows (Liang et al., 2019). Body condition score during PP also has an effect on the gene expression and protein abundance of $\mathrm{NrF} 2$; in a study that divided cows at $28 \mathrm{~d}$ prepartum to those with high BCS $(3.75 \pm 0.25)$ or normal BCS $(3.07 \pm 0.07)$, ROS concentrations and overall total protein abundance of Nrf2 were greater in subcutaneous AT of cows with high BCS. However, mRNA abundance of Nrf2 was lower, and CUL3 (cullin 3), a negative regulator of Nrf2, was greater in high- versus normal-BCS cows (Liang et al., 2020). In addition, high-BCS cows exhibited a decrease in the activity of the Nrf2-mediated antioxidant response in AT as the ratio of phosphorylated Nrf2 to total Nrf2 was lower in these cows (Liang et al., 2020). In conclusion, the Nrf2mediated antioxidant response is evident at the protein level in AT of dairy cows and probably is regulated posttranscriptionally. The Nrf2-mediated antioxidant response seems to protect the AT from oxidative damage and negatively regulate intracellular ROS levels.

\section{Role of Glutathione Antioxidant Pathway in AT}

Increased levels of antioxidants and antioxidant enzymes GSH and GSH peroxidases are positive indicators of a smooth transition into lactation in PP cows. In AT of prepartum dairy cows, the abundance of several proteins related to GSH antioxidants is lower in heatstressed (summer calving) cows than those calving in winter (Zachut et al., 2017b). Lower GSH abundance may lead to reduced Nrf2 activity as demonstrated in cows, rodents, and humans (Picklo et al., 2015; Zachut et al., 2020). As stated above, feeding transition dairy cows with rumen-protected methionine resulted in increased abundance of the GSH-related proteins in AT (Liang et al., 2019), and protein abundance of GSTM1 was greater in AT of high-BCS versus low-BCS cows (Liang et al., 2020). These findings suggest that the increased abundance and activity of glutathione-related antioxidant proteins in AT are critical components of the antioxidant systems in PP dairy cows.

\section{CONCLUSIONS}

Periparturient lipid mobilization is characterized by increased lipolysis and reduced lipogenesis in AT. Lipolysis is an inflammatory event that induces immune cell infiltration with macrophages as the predominant population. At the same time, lipolysis enhances FR

\section{Adipose tissue lipolysis}

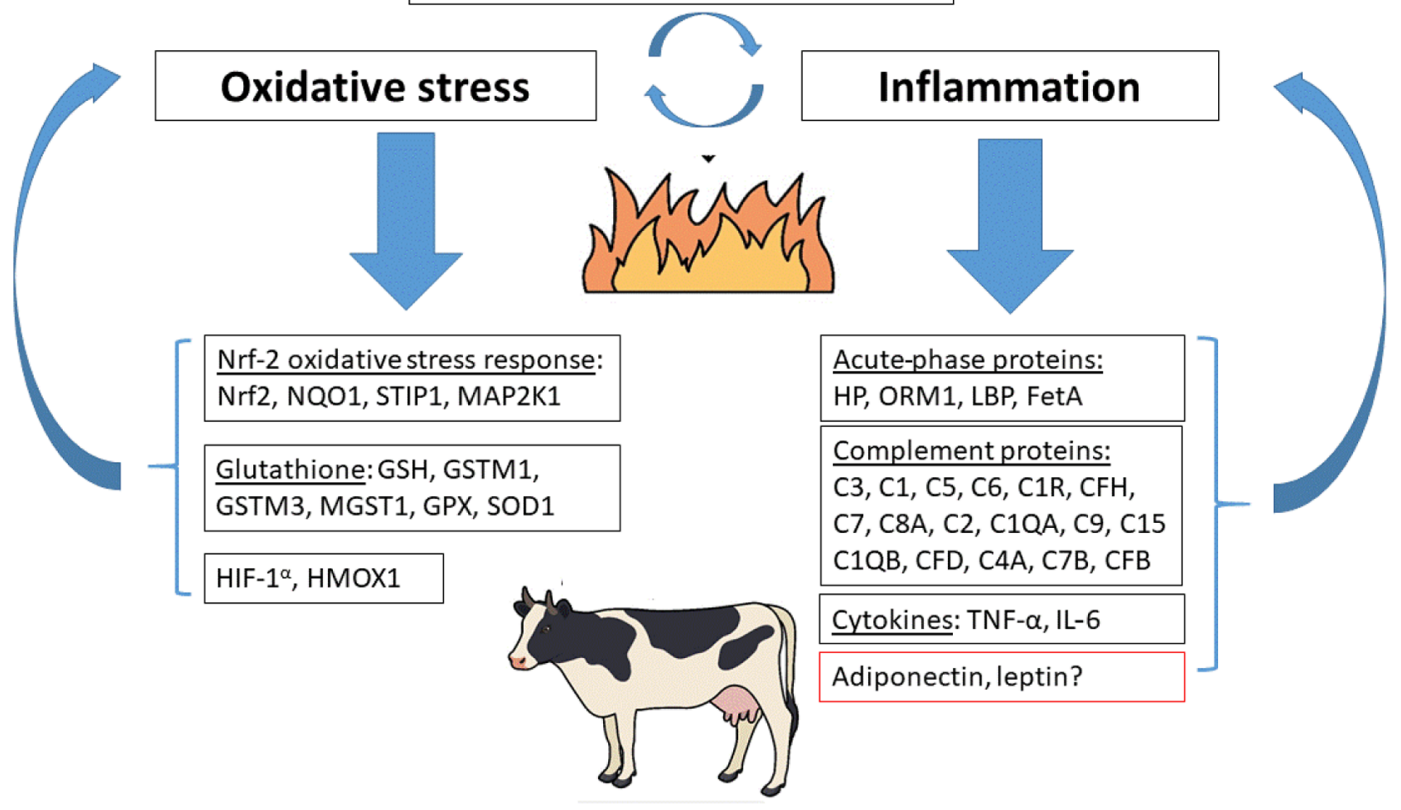

Figure 1. Diagram of proteins related to adipose tissue inflammation and oxidative stress in dairy cows. The red box indicates the roles of adiponectin and leptin in adipose inflammation are not completely understood. 
production and, when intense and protracted, will predispose the AT to OS. Adipokines orchestrate the regulation of the inflammatory process and OS responses in AT. Recent omics studies highlight APP signaling, the complement cascade, and proinflammatory cytokines as key regulators of AT adaptation to the PP environment. In addition, novel biomarkers of systemic and AT inflammation were identified by omics approaches (summarized in Figure 1), and these could be used to further investigate AT biology in periparturient cows. Limiting AT lipolysis intensity and duration by nutrition, management, or genetic selection will improve $\mathrm{PP}$ cow health. More research is needed to define the mechanisms leading to dysregulated inflammation and lipolysis in AT and how adipose depot location may affect these processes. This knowledge will support the development of nutritional and pharmacological tools to modulate PP AT function.

\section{ACKNOWLEDGMENTS}

Work presented as part of this review by the authors was funded by the Agriculture and Food Research Initiative Competitive Grants Programs of the USDA National Institute for Food and Agriculture (Washington, DC) project 2019-67015-29443, and by the Israeli Dairy Board (Yehud, Israel) grant 362-0460 and the Israeli Chief Scientist of Agriculture (Rishon Lezion, Israel) grant 20-04-0031. The authors thank the ADSA annual meeting program committee for the opportunity to contribute this talk to the symposium and Sabine Mann (Cornell University, Ithaca, NY) for critical reading of the manuscript. The authors have not stated any conflicts of interest.

\section{REFERENCES}

Abd Eldaim, M. A., Y. Okamatsu-Ogura, A. Terao, and K. Kimura. 2010. Effects of retinoic acid and hydrogen peroxide on sterol regulatory element-binding protein-1a activation during adipogenic differentiation of 3T3-L1 cells. Jpn. J. Vet. Res. 58:149-154.

Abou-Rjeileh, U., and G. A. Contreras. 2021. Redox regulation of lipid mobilization in adipose tissues. Antioxidants 10:1090.

Akter, S. H., S. Häussler, S. Dänicke, U. Müller, D. von Soosten, J. Rehage, and H. Sauerwein. 2011. Physiological and conjugated linoleic acid-induced changes of adipocyte size in different fat depots of dairy cows during early lactation. J. Dairy Sci. 94:2871-2882. https://doi.org/10.3168/jds.2010-3868.

Alharthi, A., Z. Zhou, V. Lopreiato, E. Trevisi, and J. J. Loor. 2018. Body condition score prior to parturition is associated with plasma and adipose tissue biomarkers of lipid metabolism and inflammation in Holstein cows. J. Anim. Sci. Biotechnol. 9:12. https://doi .org/10.1186/s40104-017-0221-1.

Ampem, G., H. Azegrouz, Á. Bacsadi, L. Balogh, S. Schmidt, J. Thuróczy, and T. Röszer. 2016. Adipose tissue macrophages in non-rodent mammals: A comparative study. Cell Tissue Res. 363:461-478. https://doi.org/10.1007/s00441-015-2253-1.
Arner, P., and D. Langin. 2014. Lipolysis in lipid turnover, cancer cachexia, and obesity-induced insulin resistance. Trends Endocrinol. Metab. 25:255-262. https://doi.org/10.1016/j.tem.2014.03.002.

Bradford, B. J., and T. H. Swartz. 2020. Review: Following the smoke signals: Inflammatory signaling in metabolic homeostasis and homeorhesis in dairy cattle. Animal 14:s144-s154.

Bradford, B. J., K. Yuan, J. K. Farney, L. K. Mamedova, and A. J. Carpenter. 2015. Invited review: Inflammation during the transition to lactation: New adventures with an old flame. J. Dairy Sci. 98:6631-6650. https://doi.org/10.3168/jds.2015-9683.

Brown, W. E., and B. J. Bradford. 2021. Invited review: Mechanisms of hypophagia during disease. J. Dairy Sci. 104:9418-9436. https:/ /doi.org/10.3168/jds.2021-20217.

Cao, Y. 2013. Angiogenesis and vascular functions in modulation of obesity, adipose metabolism, and insulin sensitivity. Cell Metab. 18:478-489. https://doi.org/10.1016/j.cmet.2013.08.008.

Capel, F., E. Klimčáková, N. Viguerie, B. Roussel, M. Vítková, M. Kováčiková, J. Polák, Z. Kováčová, J. Galitzky, J.-J. Maoret, J. Hanáček, T. H. Pers, A. Bouloumié, V. Štich, and D. Langin. 2009. Macrophages and adipocytes in human obesity. Diabetes 58:15581567. https://doi.org/10.2337/db09-0033.

Ceciliani, F., J. J. Ceron, P. D. Eckersall, and H. Sauerwein. 2012. Acute phase proteins in ruminants. J. Proteomics 75:4207-4231. https://doi.org/10.1016/j.jprot.2012.04.004.

Ceciliani, F., and C. Lecchi. 2019. The immune functions of $\alpha(1)$ acid glycoprotein. Curr. Protein Pept. Sci. 20:505-524. https://doi.org/ 10.2174/1389203720666190405101138.

Chilliard, Y., C. Delavaud, and M. Bonnet. 2005. Leptin expression in ruminants: Nutritional and physiological regulations in relation with energy metabolism. Domest. Anim. Endocrinol. 29:3-22. https://doi.org/10.1016/j.domaniend.2005.02.026.

Choi, M. S., J. Y. Jung, H. J. Kim, M. R. Ham, T. R. Lee, and D. W. Shin. 2016. S-nitrosylation of fatty acid synthase regulates its activity through dimerization. J. Lipid Res. 57:607-615. https:// doi.org/10.1194/jlr.M065805.

Cohen, G., Y. Riahi, and S. Sasson. 2011. Lipid peroxidation of polyunsaturated fatty acids in normal and obese adipose tissues. Arch. Physiol. Biochem. 117:131-139. https://doi.org/10.3109/13813455 .2011.557387.

Colitti, M., B. Stefanon, G. Gabai, M. E. Gelain, and F. Bonsembiante. 2019. Oxidative stress and nutraceuticals in the modulation of the immune function: current knowledge in animals of veterinary interest. Antioxidants 8:28.

Collins, Y., E. T. Chouchani, A. M. James, K. E. Menger, H. M. Cocheme, and M. P. Murphy. 2012. Mitochondrial redox signalling at a glance. J. Cell Sci. 125:801-806. https://doi.org/10.1242/jcs .098475 .

Contreras, G. A., J. De Koster, J. de Souza, J. Laguna, V. Mavangira, R. K. Nelli, J. Gandy, A. L. Lock, and L. M. Sordillo. 2020. Lipolysis modulates the biosynthesis of inflammatory lipid mediators derived from linoleic acid in adipose tissue of periparturient dairy cows. J. Dairy Sci. 103:1944-1955. https://doi.org/10.3168/ jds.2019-17256.

Contreras, G. A., K. Thelen, S. Schmidt, C. Strieder-Barboza, C. Preseault, R. Raphael, M. Kiupel, J. Caron, and A. Lock. 2016. Adipose tissue remodeling in late-lactation dairy cows during feed restriction-induced negative energy balance. J. Dairy Sci. 99:10009-10021. https://doi.org/10.3168/jds.2016-11552.

Contreras, G. A., E. Kabara, J. Brester, L. Neuder, and M. Kiupel. 2015. Macrophage infiltration in the omental and subcutaneous adipose tissues of dairy cows with displaced abomasum. J. Dairy Sci. 98:6176-6187. https://doi.org/10.3168/jds.2015-9370.

Contreras, G. A., C. Strieder-Barboza, and J. De Koster. 2018. Symposium review: Modulating adipose tissue lipolysis and remodeling to improve immune function during the transition period and early lactation of dairy cows. J. Dairy Sci. 101:2737-2752. https://doi .org/10.3168/jds.2017-13340.

Contreras, G. A., C. Strieder-Barboza, J. de Souza, J. Gandy, V. Mavangira, A. L. Lock, and L. M. Sordillo. 2017a. Periparturient li- 
polysis and oxylipid biosynthesis in bovine adipose tissues. PLoS One 12:e0188621. https://doi.org/10.1371/journal.pone.0188621.

Contreras, G. A., C. Strieder-Barboza, and W. Raphael. 2017b. Adipose tissue lipolysis and remodeling during the transition period of dairy cows. J. Anim. Sci. Biotechnol. 8:41. https://doi.org/10 $.1186 / \mathrm{s} 40104-017-0174-4$.

De Koster, J., C. Strieder-Barboza, J. de Souza, A. L. Lock, and G. A. Contreras. 2018. Short communication: Effects of body fat mobilization on macrophage infiltration in adipose tissue of early lactation dairy cows. J. Dairy Sci. 101:7608-7613. https://doi.org/10 $.3168 /$ jds.2017-14318.

Den Hartigh, L. J., M. Omer, L. Goodspeed, S. Wang, T. Wietecha, K. D. O'Brien, and C. Y. Han. 2017. Adipocyte-specific deficiency of NADPH oxidase 4 delays the onset of insulin resistance and attenuates adipose tissue inflammation in obesity. Arterioscler. Thromb. Vasc. Biol. 37:466-475. https://doi.org/10.1161/ ATVBAHA.116.308749.

Depreester, E., J. De Koster, M. Van Poucke, M. Hostens, W. Van den Broeck, L. Peelman, G. A. Contreras, and G. Opsomer. 2018. Influence of adipocyte size and adipose depot on the number of adipose tissue macrophages and the expression of adipokines in dairy cows at the end of pregnancy. J. Dairy Sci. 101:6542-6555. https://doi.org/10.3168/jds.2017-13777.

DeYulia, G. J. Jr., J. M. Cárcamo, O. Bórquez-Ojeda, C. C. Shelton, and D. W. Golde. 2005. Hydrogen peroxide generated extracellularly by receptor-ligand interaction facilitates cell signaling. Proc. Natl. Acad. Sci. USA 102:5044-5049. https://doi.org/10.1073/ pnas. 0501154102 .

Dirandeh, E., M. Ghorbanalinia, A. Rezaei-Roodbari, and M. G. Colazo. 2020. Relationship between body condition score loss and mRNA of genes related to fatty acid metabolism and the endocannabinoid system in adipose tissue of periparturient cows. Animal 14:1724-1732.

Duncan, R. E., E. Sarkadi-Nagy, K. Jaworski, M. Ahmadian, and H. S. Sul. 2008. Identification and functional characterization of adipose-specific phospholipase A2 (AdPLA). J. Biol. Chem. 283:25428-25436. https://doi.org/10.1074/jbc.M804146200.

Fonseca-Alaniz, M. H., J. Takada, M. I. Alonso-Vale, and F. B. Lima. 2007. Adipose tissue as an endocrine organ: From theory to practice. J. Pediatr. (Rio J.) 83(Suppl. 5):S192-S203. https://doi.org/ 10.1590/S0021-75572007000700011.

Gartung, A., J. Zhao, S. Chen, E. Mottillo, G. C. VanHecke, Y. H. Ahn, K. R. Maddipati, A. Sorokin, J. Granneman, and M. J. Lee. 2016. Characterization of eicosanoids produced by adipocyte lipolysis. J. Biol. Chem. 291:16001-16010. https://doi.org/10.1074/ jbc.M116.725937.

Grant, R. W., and J. M. Stephens. 2015. Fat in flames: Influence of cytokines and pattern recognition receptors on adipocyte lipolysis. Am. J. Physiol. Endocrinol. Metab. 309:E205-E213. https://doi .org/10.1152/ajpendo.00053.2015.

Gutsmann, T., M. Müller, S. F. Carroll, R. C. MacKenzie, A. Wiese, and U. Seydel. 2001. Dual role of lipopolysaccharide (LPS)-binding protein in neutralization of LPS and enhancement of LPS-induced activation of mononuclear cells. Infect. Immun. 69:6942-6950. https://doi.org/10.1128/IAI.69.11.6942-6950.2001.

Han van der Kolk, J. H., J. J. Gross, V. Gerber, and R. M. Bruckmaier. 2017. Disturbed bovine mitochondrial lipid metabolism: A review. Vet. Q. 37:262-273. https://doi.org/10.1080/01652176 .2017 .1354561 .

Hansen, M., M. T. Lund, E. Gregers, R. Kraunsøe, G. Van Hall, J. W. Helge, and F. Dela. 2015. Adipose tissue mitochondrial respiration and lipolysis before and after a weight loss by diet and RYGB. Obesity (Silver Spring) 23:2022-2029. https://doi.org/10.1002/oby .21223.

Hardie, D. G., F. A. Ross, and S. A. Hawley. 2012. AMPK: a nutrient and energy sensor that maintains energy homeostasis. Nat. Rev. Mol. Cell Biol. 13:251-262. https://doi.org/10.1038/nrm3311.

Hersoug, L. G., P. Møller, and S. Loft. 2016. Gut microbiota-derived lipopolysaccharide uptake and trafficking to adipose tissue: Implications for inflammation and obesity. Obes. Rev. 17:297-312. https://doi.org/10.1111/obr.12370.
Higuchi, M., G. J. Dusting, H. Peshavariya, F. Jiang, S. T. Hsiao, E. C. Chan, and G. S. Liu. 2013. Differentiation of human adipose-derived stem cells into fat involves reactive oxygen species and Forkhead box O1 mediated upregulation of antioxidant enzymes. Stem Cells Dev. 22:878-888. https://doi.org/10.1089/scd.2012.0306.

Hotamisligil, G. S., P. Arner, J. F. Caro, R. L. Atkinson, and B. M. Spiegelman. 1995. Increased adipose tissue expression of tumor necrosis factor-alpha in human obesity and insulin resistance. J. Clin. Invest. 95:2409-2415. https://doi.org/10.1172/JCI117936.

Hotamisligil, G. S., N. S. Shargill, and B. M. Spiegelman. 1993. Adipose expression of tumor necrosis factor-alpha: direct role in obesity-linked insulin resistance. Science 259:87-91. https://doi.org/ 10.1126/science. 7678183 .

Humphries, K. M., C. Juliano, and S. S. Taylor. 2002. Regulation of cAMP-dependent protein kinase activity by glutathionylation. J. Biol. Chem. 277:43505-43511. https://doi.org/10.1074/jbc .M207088200.

Jaitin, D. A., L. Adlung, C. A. Thaiss, A. Weiner, B. Li, H. Descamps, P. Lundgren, C. Bleriot, Z. Liu, A. Deczkowska, H. Keren-Shaul, E. David, N. Zmora, S. M. Eldar, N. Lubezky, O. Shibolet, D. A. Hill, M. A. Lazar, M. Colonna, F. Ginhoux, H. Shapiro, E. Elinav, and I. Amit. 2019. Lipid-associated macrophages control metabolic homeostasis in a Trem2-dependent manner. Cell 178:686-698. https://doi.org/10.1016/j.cell.2019.05.054.

Jarc, E., and T. Petan. 2019. Lipid droplets and the management of cellular stress. Yale J. Biol. Med. 92:435-452.

Jedrychowski, M. P., L. Liu, C. J. Laflamme, K. Karastergiou, T. Meshulam, S. Y. Ding, Y. Wu, M. J. Lee, S. P. Gygi, S. K. Fried, and P. F. Pilch. 2015. Adiporedoxin, an upstream regulator of ER oxidative folding and protein secretion in adipocytes. Mol. Metab. 4:758-770. https://doi.org/10.1016/j.molmet.2015.09.002.

Kabara, E., L. M. Sordillo, S. Holcombe, and G. A. Contreras. 2014. Adiponectin links adipose tissue function and monocyte inflammatory responses during bovine metabolic stress. Comp. Immunol Microbiol. Infect. Dis. 37:49-58. https://doi.org/10.1016/j.cimid .2013.10.007.

Kaspar, J. W., S. K. Niture, and A. K. Jaiswal. 2009. Nrf2:INrf2 (Keap1) signaling in oxidative stress. Free Radic. Biol. Med. 47:1304-1309. https://doi.org/10.1016/j.freeradbiomed.2009.07 .035 .

Kelley, E. E., N. K. Khoo, N. J. Hundley, U. Z. Malik, B. A. Freeman, and M. M. Tarpey. 2010. Hydrogen peroxide is the major oxidant product of xanthine oxidase. Free Radic. Biol. Med. 48:493-498. https://doi.org/10.1016/j.freeradbiomed.2009.11.012.

Khiaosa-Ard, R., and Q. Zebeli. 2018. Diet-induced inflammation: From gut to metabolic organs and the consequences for the health and longevity of ruminants. Res. Vet. Sci. 120:17-27. https://doi .org/10.1016/j.rvsc.2018.08.005.

Kosteli, A., E. Sugaru, G. Haemmerle, J. F. Martin, J. Lei, R. Zechner, and A. W. Ferrante Jr.. 2010. Weight loss and lipolysis promote a dynamic immune response in murine adipose tissue. J. Clin. Invest. 120:3466-3479. https://doi.org/10.1172/JCI42845.

Krautbauer, S., K. Eisinger, Y. Hader, M. Neumeier, and C. Buechler. 2014. Manganese superoxide dismutase knock-down in 3T3-L1 preadipocytes impairs subsequent adipogenesis. Mol. Cell. Biochem. 393:69-76. https://doi.org/10.1007/s11010-014-2047-x.

Lamping, N., R. Dettmer, N. W. Schröder, D. Pfeil, W. Hallatschek, R. Burger, and R. R. Schumann. 1998. LPS-binding protein protects mice from septic shock caused by LPS or gram-negative bacteria. J. Clin. Invest. 101:2065-2071. https://doi.org/10.1172/JCI2338.

Laubenthal, L., L. Ruda, N. Sultana, J. Winkler, J. Rehage, U. Meyer, S. Dänicke, H. Sauerwein, and S. Häussler. 2017. Effect of increasing body condition on oxidative stress and mitochondrial biogenesis in subcutaneous adipose tissue depot of nonlactating dairy cows. J. Dairy Sci. 100:4976-4986. https://doi.org/10.3168/jds .2016-12356.

Lavrovsky, Y., B. Chatterjee, R. A. Clark, and A. K. Roy. 2000. Role of redox-regulated transcription factors in inflammation, aging and age-related diseases. Exp. Gerontol. 35:521-532. https://doi.org/ 10.1016/S0531-5565(00)00118-2. 
Lee, B., and J. Shao. 2014. Adiponectin and energy homeostasis. Rev. Endocr. Metab. Disord. 15:149-156. https://doi.org/10.1007/ s11154-013-9283-3.

Lee, Y.-H., S.-N. Kim, H.-J. Kwon, K. R. Maddipati, and J. G. Granneman. 2016. Adipogenic role of alternatively activated macrophages in $\beta$-adrenergic remodeling of white adipose tissue. Am. J. Physiol. Regul. Integr. Comp. Physiol. 310:R55-R65. https:// doi.org/10.1152/ajpregu.00355.2015.

Lee, Y.-H., A. Petkova, and J. Granneman. 2013. Identification of an adipogenic niche for adipose tissue remodeling and restoration. Cell Metab. 18:355-367. https://doi.org/10.1016/j.cmet.2013.08 .003 .

Li, P., Z. Zhu, Y. Lu, and J. G. Granneman. 2005. Metabolic and cellular plasticity in white adipose tissue II: role of peroxisome proliferator-activated receptor-alpha. Am. J. Physiol. Endocrinol. Metab. 289:E617-E626.

Liang, Y., A. S. Alharthi, R. Bucktrout, A. A. Elolimy, V. Lopreiato, I. Martinez-Cortés, C. Xu, C. Fernandez, E. Trevisi, and J. J. Loor. 2020. Body condition alters glutathione and nuclear factor erythroid 2-like 2 (NFE2L2)-related antioxidant network abundance in subcutaneous adipose tissue of periparturient Holstein cows. J. Dairy Sci. 103:6439-6453. https://doi.org/10.3168/jds.2019-17813.

Liang, Y., F. Batistel, C. Parys, and J. J. Loor. 2019. Glutathione metabolism and nuclear factor erythroid 2-like 2 (NFE2L2)-related proteins in adipose tissue are altered by supply of ethyl-cellulose rumen-protected methionine in peripartal Holstein cows. J. Dairy Sci. 102:5530-5541. https://doi.org/10.3168/jds.2018-15687.

Liu, J., W. Lu, B. Shi, S. Klein, and X. Su. 2019. Peroxisomal regulation of redox homeostasis and adipocyte metabolism. Redox Biol. 24:101167. https://doi.org/10.1016/j.redox.2019.101167.

Lopreiato, V., A. Hosseini, F. Rosa, Z. Zhou, A. Alharthi, E. Trevisi, and J. J. Loor. 2018. Dietary energy level affects adipose depot mass but does not impair in vitro subcutaneous adipose tissue response to short-term insulin and tumor necrosis factor- $\alpha$ challenge in nonlactating, nonpregnant Holstein cows. J. Dairy Sci. 101:10206-10219. https://doi.org/10.3168/jds.2018-14389.

Lykkesfeldt, J., and O. Svendsen. 2007. Oxidants and antioxidants in disease: Oxidative stress in farm animals. Vet. J. 173:502-511. https://doi.org/10.1016/j.tvjl.2006.06.005.

Mahajan, S., H. K. Dkhar, V. Chandra, S. Dave, R. Nanduri, A. K. Janmeja, J. N. Agrewala, and P. Gupta. 2012. Mycobacterium tuberculosis modulates macrophage lipid-sensing nuclear receptors PPAR $\gamma$ and TR4 for survival. J. Immunol. 188:5593-5603. https:/ /doi.org/10.4049/jimmunol.1103038.

Mann, S., D. V. Nydam, A. Abuelo, F. A. Leal Yepes, T. R. Overton, and J. J. Wakshlag. 2016. Insulin signaling, inflammation, and lipolysis in subcutaneous adipose tissue of transition dairy cows either overfed energy during the prepartum period or fed a controlled-energy diet. J. Dairy Sci. 99:6737-6752. https://doi.org/10 .3168/jds.2016-10969.

Martel, C. A., L. K. Mamedova, J. E. Minton, M. L. Jones, J. A. Carroll, and B. J. Bradford. 2014. Continuous low-dose infusion of tumor necrosis factor alpha in adipose tissue elevates adipose tissue interleukin 10 abundance and fails to alter metabolism in lactating dairy cows. J. Dairy Sci. 97:4897-4906. https://doi.org/ 10.3168/jds.2013-7777.

Mavangira, V., and L. M. Sordillo. 2018. Role of lipid mediators in the regulation of oxidative stress and inflammatory responses in dairy cattle. Res. Vet. Sci. 116:4-14. https://doi.org/10.1016/j.rvsc.2017 .08 .002 .

May, J. M., and C. de Haën. 1979. The insulin-like effect of hydrogen peroxide on pathways of lipid synthesis in rat adipocytes. J. Biol. Chem. 254:9017-9021. https://doi.org/10.1016/S0021 -9258(19)86803-5.

McFadden, J. 2020. Review: Lipid biology in the periparturient dairy cow: contemporary perspectives. Animal 14:S165-S175.

McFadden, J. W., and J. E. Rico. 2019. Invited review: Sphingolipid biology in the dairy cow: The emerging role of ceramide. J. Dairy Sci. 102:7619-7639. https://doi.org/10.3168/jds.2018-16095.

McMurray, F., D. A. Patten, and M. E. Harper. 2016. Reactive oxygen species and oxidative stress in obesity-recent findings and empiri- cal approaches. Obesity (Silver Spring) 24:2301-2310. https://doi .org/10.1002/oby.21654.

Mellouk, N., C. Rame, D. Naquin, Y. Jaszczyszyn, J. L. Touzé, E. Briant, D. Guillaume, T. Ntallaris, P. Humblot, and J. Dupont. 2019. Impact of the severity of negative energy balance on gene expression in the subcutaneous adipose tissue of periparturient primiparous Holstein dairy cows: Identification of potential novel metabolic signals for the reproductive system. PLoS One 14:e0222954. https://doi.org/10.1371/journal.pone.0222954.

Minuti, A., M. Bionaz, V. Lopreiato, N. A. Janovick, S. L. RodriguezZas, J. K. Drackley, and J. J. Loor. 2020. Prepartum dietary energy intake alters adipose tissue transcriptome profiles during the periparturient period in Holstein dairy cows. J. Anim. Sci. Biotechnol. 11:1. https://doi.org/10.1186/s40104-019-0409-7.

Montgomery, S. R., L. K. Mamedova, M. Zachut, G. Kra, S. Häussler, M. Vaughn, J. Gonzalez, and B. J. Bradford. 2019. Effects of sodium salicylate on glucose kinetics and insulin signaling in postpartum dairy cows. J. Dairy Sci. 102:1617-1629. https://doi.org/ 10.3168/jds.2018-15312.

Mukesh, M., M. Bionaz, D. E. Graugnard, J. K. Drackley, and J. J. Loor. 2010. Adipose tissue depots of Holstein cows are immune responsive: Inflammatory gene expression in vitro. Domest. Anim. Endocrinol. 38:168-178. https://doi.org/10.1016/j.domaniend .2009.10.001.

Müller, G., S. Wied, J. Straub, and C. Jung. 2008. Coordinated regulation of esterification and lipolysis by palmitate, $\mathrm{H}_{2} \mathrm{O}_{2}$ and the antidiabetic sulfonylurea drug, glimepiride, in rat adipocytes. Eur. J. Pharmacol. 597:6-18. https://doi.org/10.1016/j.ejphar.2008.08 .034 .

Murphy, M. P. 2009. How mitochondria produce reactive oxygen species. Biochem. J. 417:1-13. https://doi.org/10.1042/BJ20081386.

Myers, M. N., M. Zachut, J. Tam, and G. A. Contreras. 2021. A proposed modulatory role of the endocannabinoid system on adipose tissue metabolism and appetite in periparturient dairy cows. J. Anim. Sci. Biotechnol. 12:21. https://doi.org/10.1186/s40104-021 $-00549-3$.

Napier, J. A., L. V. Michaelson, and O. Sayanova. 2003. The role of cytochrome b5 fusion desaturases in the synthesis of polyunsaturated fatty acids. Prostaglandins Leukot. Essent. Fatty Acids 68:135-143. https://doi.org/10.1016/S0952-3278(02)00263-6.

Newman, A. W., A. Miller, F. A. Leal Yepes, E. Bitsko, D. Nydam, and S. Mann. 2019. The effect of the transition period and postpartum body weight loss on macrophage infiltrates in bovine subcutaneous adipose tissue. J. Dairy Sci. 102:1693-1701. https://doi .org/10.3168/jds.2018-15362.

Obinata, H., T. Hattori, S. Nakane, K. Tatei, and T. Izumi. 2005. Identification of 9-hydroxyoctadecadienoic acid and other oxidized free fatty acids as ligands of the $\mathrm{G}$ protein-coupled receptor G2A. J. Biol. Chem. 280:40676-40683. https://doi.org/10.1074/ jbc.M507787200.

Picklo, M. J., E. K. Long, and E. E. Vomhof-DeKrey. 2015. Glutathionyl systems and metabolic dysfunction in obesity. Nutr. Rev. 73:858-868. https://doi.org/10.1093/nutrit/nuv042.

Rahman, M. M., C. Lecchi, H. Sauerwein, M. Mielenz, S. Häußler, L. Restelli, C. Giudice, and F. Ceciliani. 2015. Expression of a1-acid glycoprotein and lipopolysaccharide binding protein in visceral and subcutaneous adipose tissue of dairy cattle. Vet. J. 203:223-227. https://doi.org/10.1016/j.tvjl.2014.12.001.

Rambacher, K. M., and N. H. Moniri. 2020. The $\beta 2$-adrenergic receptor-ROS signaling axis: An overlooked component of $\beta 2 \mathrm{AR}$ function? Biochem. Pharmacol. 171:113690. https://doi.org/10.1016/j .bcp.2019.113690.

Ribiere, C., A. M. Jaubert, N. Gaudiot, D. Sabourault, M. L. Marcus, J. L. Boucher, D. Denis-Henriot, and Y. Giudicelli. 1996. White adipose tissue nitric oxide synthase: A potential source for NO production. Biochem. Biophys. Res. Commun. 222:706-712. https: //doi.org/10.1006/bbrc.1996.0824.

Ricklin, D., E. S. Reis, D. C. Mastellos, P. Gros, and J. D. Lambris. 2016. Complement component C3 - The "Swiss Army Knife" of innate immunity and host defense. Immunol. Rev. 274:33-58. https: //doi.org/10.1111/imr.12500. 
Russo, L., and C. N. Lumeng. 2018. Properties and functions of adipose tissue macrophages in obesity. Immunology 155:407-417. https://doi.org/10.1111/imm.13002.

Sadri, H., R. M. Bruckmaier, H. R. Rahmani, G. R. Ghorbani, I. Morel, and H. A. van Dorland. 2010. Gene expression of tumour necrosis factor and insulin signalling-related factors in subcutaneous adipose tissue during the dry period and in early lactation in dairy cows. J. Anim. Physiol. Anim. Nutr. (Berl.) 94:e194-e202. https://doi.org/10.1111/j.1439-0396.2010.01005.x.

Sadri, H., M. Mielenz, I. Morel, R. M. Bruckmaier, and H. A. van Dorland. 2011. Plasma leptin and mRNA expression of lipogenesis and lipolysis-related factors in bovine adipose tissue around parturition. J. Anim. Physiol. Anim. Nutr. (Berl.) 95:790-797. https:// doi.org/10.1111/j.1439-0396.2010.01111.x.

Salcedo-Tacuma, D., J. Parales-Giron, C. Prom, M. Chirivi, J. Laguna, A. L. Lock, and G. A. Contreras. 2020. Transcriptomic profiling of adipose tissue inflammation, remodeling, and lipid metabolism in periparturient dairy cows (Bos taurus). BMC Genomics 21:824. https://doi.org/10.1186/s12864-020-07235-0.

Saremi, B., A. Al-Dawood, S. Winand, U. Müller, J. Pappritz, D. von Soosten, J. Rehage, S. Dänicke, S. Häussler, M. Mielenz, and H. Sauerwein. 2012. Bovine haptoglobin as an adipokine: Serum concentrations and tissue expression in dairy cows receiving a conjugated linoleic acids supplement throughout lactation. Vet. Immunol. Immunopathol. 146:201-211. https://doi.org/10.1016/j .vetimm.2012.03.011.

Sauerwein, H., E. Bendixen, L. Restelli, and F. Ceciliani. 2014. The adipose tissue in farm animals: A proteomic approach. Curr. Protein Pept. Sci. 15:146-155. https://doi.org/10.2174/ 1389203715666140221123105.

Sauerwein, H., and S. Häußler. 2016. Endogenous and exogenous factors influencing the concentrations of adiponectin in body fluids and tissues in the bovine. Domest. Anim. Endocrinol. 56(Suppl):S33S43. https://doi.org/10.1016/j.domaniend.2015.11.007.

Schneider, K. S., and J. Y. Chan. 2013. Emerging role of Nrf2 in adipocytes and adipose biology. Adv. Nutr. 4:62-66.

Schröder, K., K. Wandzioch, I. Helmcke, and R. P. Brandes. 2009. Nox4 acts as a switch between differentiation and proliferation in preadipocytes. Arterioscler. Thromb. Vasc. Biol. 29:239-245. https://doi.org/10.1161/ATVBAHA.108.174219.

Silver, R. J. 2019. The endocannabinoid system of animals. Animals (Basel) 9:686.

Singh, S. P., S. Häussler, J. F. Heinz, B. Saremi, B. Mielenz, J. Rehage, S. Dänicke, M. Mielenz, and H. Sauerwein. 2014. Supplementation with conjugated linoleic acids extends the adiponectin deficit during early lactation in dairy cows. Gen. Comp. Endocrinol. 198:13-21. https://doi.org/10.1016/j.ygcen.2013.12.008.

Song, Y. S., D. H. Lee, J. H. Yu, D. K. Oh, J. T. Hong, and D. Y. Yoon. 2016. Promotion of adipogenesis by 15-(S)-hydroxyeicosatetraenoic acid. Prostaglandins Other Lipid Mediat. 123:1-8. https://doi.org/10.1016/j.prostaglandins.2016.02.001.

Sordillo, L. M. 2018. Symposium review: Oxylipids and the regulation of bovine mammary inflammatory responses. J. Dairy Sci. 101:5629-5641. https://doi.org/10.3168/jds.2017-13855.

Sordillo, L. M., and S. L. Aitken. 2009. Impact of oxidative stress on the health and immune function of dairy cattle. Vet. Immunol. Immunopathol. 128:104-109. https://doi.org/10.1016/j.vetimm.2008 .10 .305 .

Strieder-Barboza, C., and G. A. Contreras. 2019. Fetuin-A modulates lipid mobilization in bovine adipose tissue by enhancing lipogenic activity of adipocytes. J. Dairy Sci. 102:4628-4638. https://doi .org/10.3168/jds.2018-15808.

Strieder-Barboza, C., J. de Souza, W. Raphael, A. L. Lock, and G. A. Contreras. 2018. Fetuin-A: A negative acute-phase protein linked to adipose tissue function in periparturient dairy cows. J. Dairy Sci. 101:2602-2616. https://doi.org/10.3168/jds.2017-13644.

Sun, Y., Y. Yang, Z. Qin, J. Cai, X. Guo, Y. Tang, J. Wan, D.-F. Su, and X. Liu. 2016. The acute-phase protein orosomucoid regulates food intake and energy homeostasis via leptin receptor signaling pathway. Diabetes 65:1630-1641. https://doi.org/10.2337/db15 -1193 .
Takiya, C., S. Montgomery, L. Mamedova, G. Kra, N. Nemes-Navon, Y. Levin, S. Fleming, B. Bradford, and M. Zachut. 2019a. Proteomic analysis reveals greater abundance of complement and inflammatory proteins in subcutaneous adipose tissue from postpartum cows treated with sodium salicylate. J. Proteomics 204:103399. https://doi.org/10.1016/j.jprot.2019.103399.

Takiya, C., S. Montgomery, L. Mamedova, G. Kra, N. Nemes-Navon, Y. Levin, S. Fleming, B. Bradford, and M. Zachut. 2019b. Proteome dataset of subcutaneous adipose tissue from postpartum cows treated with sodium salicylate. Data Brief 26:104567. https:/ /doi.org/10.1016/j.dib.2019.104567.

Tan, H. Y., N. Wang, S. Li, M. Hong, X. Wang, and Y. Feng. 2016. The reactive oxygen species in macrophage polarization: Reflecting its dual role in progression and treatment of human diseases. Oxid. Med. Cell. Longev. 2016:2795090. https://doi.org/10.1155/ 2016/2795090.

Tormos, K. V., E. Anso, R. B. Hamanaka, J. Eisenbart, J. Joseph, B. Kalyanaraman, and N. S. Chandel. 2011. Mitochondrial complex III ROS regulate adipocyte differentiation. Cell Metab. 14:537544. https://doi.org/10.1016/j.cmet.2011.08.007.

Townsend, L. K., A. J. Weber, P. A. Barbeau, G. P. Holloway, and D. C. Wright. 2020. Reactive oxygen species-dependent regulation of pyruvate dehydrogenase kinase-4 in white adipose tissue. Am. J. Physiol. Cell Physiol. 318:C137-C149. https://doi.org/10.1152/ ajpcell.00313.2019.

Umeno, A., M. Shichiri, N. Ishida, Y. Hashimoto, K. Abe, M. Kataoka, K. Yoshino, Y. Hagihara, N. Aki, M. Funaki, Y. Asada, and Y. Yoshida. 2013. Singlet oxygen induced products of linoleates, 10- and 12-(Z,E)-hydroxyoctadecadienoic acids (HODE), can be potential biomarkers for early detection of type 2 diabetes. PLoS One 8:e63542. https://doi.org/10.1371/journal.pone.0063542.

Ursini, F., and L. Abenavoli. 2018. The emerging role of complement $\mathrm{C} 3$ as a biomarker of insulin resistance and cardiometabolic diseases: preclinical and clinical evidence. Rev. Recent Clin. Trials 13:61-68. https://doi.org/10.2174/1574887112666171128134552.

Vailati-Riboni, M., G. Farina, F. Batistel, A. Heiser, M. D. Mitchell, M. A. Crookenden, C. G. Walker, J. K. Kay, S. Meier, J. R. Roche, and J. J. Loor. 2017. Far-off and close-up dry matter intake modulate indicators of immunometabolic adaptations to lactation in subcutaneous adipose tissue of pasture-based transition dairy cows. J. Dairy Sci. 100:2334-2350. https://doi.org/10.3168/jds .2016-11790.

Vailati-Riboni, M., M. Kanwal, O. Bulgari, S. Meier, N. V. Priest, C. R. Burke, J. K. Kay, S. McDougall, M. D. Mitchell, C. G. Walker, M. Crookenden, A. Heiser, J. R. Roche, and J. J. Loor. 2016. Body condition score and plane of nutrition prepartum affect adipose tissue transcriptome regulators of metabolism and inflammation in grazing dairy cows during the transition period. J. Dairy Sci. 99:758-770. https://doi.org/10.3168/jds.2015-10046.

Vangaveti, V., B. T. Baune, and R. L. Kennedy. 2010. Hydroxyoctadecadienoic acids: Novel regulators of macrophage differentiation and atherogenesis. Ther. Adv. Endocrinol. Metab. 1:51-60. https: //doi.org/10.1177/2042018810375656.

Verschoor, A., C. M. Karsten, S. P. Broadley, Y. Laumonnier, and J. Köhl. 2016. Old dogs-new tricks: Immunoregulatory properties of C3 and C5 cleavage fragments. Immunol. Rev. 274:112-126. https: //doi.org/10.1111/imr.12473.

Vigilanza, P., K. Aquilano, S. Baldelli, G. Rotilio, and M. R. Ciriolo. 2011. Modulation of intracellular glutathione affects adipogenesis in 3T3-L1 cells. J. Cell. Physiol. 226:2016-2024. https://doi.org/ $10.1002 /$ jcp. 22542 .

Wang, H., and A. E. Sama. 2012. Anti-inflammatory role of fetuin-A in injury and infection. Curr. Mol. Med. 12:625-633. https://doi .org/10.2174/156652412800620039.

Weisberg, S. P., D. McCann, M. Desai, M. Rosenbaum, R. L. Leibel, and A. W. Ferrante Jr.. 2003. Obesity is associated with macrophage accumulation in adipose tissue. J. Clin. Invest. 112:17961808. https://doi.org/10.1172/JCI200319246.

Willemsen, L., and M. P. de Winther. 2020. Macrophage subsets in atherosclerosis as defined by single-cell technologies. J. Pathol. 250:705-714. https://doi.org/10.1002/path.5392. 
Wulster-Radcliffe, M. C., K. M. Ajuwon, J. Wang, J. A. Christian, and M. E. Spurlock. 2004. Adiponectin differentially regulates cytokines in porcine macrophages. Biochem. Biophys. Res. Commun. 316:924-929. https://doi.org/10.1016/j.bbrc.2004.02.130.

Xie, W. D., H. Wang, J. F. Zhang, J. N. Li, Y. Can, L. Qing, H. F. Kung, and Y. O. Zhang. 2011. Enhanced peroxisomal B-oxidation metabolism in visceral adipose tissues of high-fat diet-fed obesityresistant C57BL/6 mice. Exp. Ther. Med. 2:309-315. https://doi .org/10.3892/etm.2011.208.

Xu, H., G. T. Barnes, Q. Yang, G. Tan, D. Yang, C. J. Chou, J. Sole, A. Nichols, J. S. Ross, L. A. Tartaglia, and H. Chen. 2003. Chronic inflammation in fat plays a crucial role in the development of obesity-related insulin resistance. J. Clin. Invest. 112:1821-1830. https://doi.org/10.1172/JCI200319451.

Xu, Q., Y. Fan, J. J. Loor, Y. Liang, X. Sun, H. Jia, C. Zhao, and C. Xu. 2021. Adenosine 5'-monophosphate-activated protein kinase ameliorates bovine adipocyte oxidative stress by inducing antioxidant responses and autophagy. J. Dairy Sci. 104:4516-4528. https: //doi.org/10.3168/jds.2020-18728.

Xu, Q., X. Li, L. Ma, J. J. Loor, D. N. Coleman, H. Jia, G. Liu, C. Xu, Y. Wang, and X. Li. 2019. Adipose tissue proteomic analysis in ketotic or healthy Holstein cows in early lactation1. J. Anim. Sci. 97:2837-2849. https://doi.org/10.1093/jas/skz132.

Yang, S., L. Guo, Y. Su, J. Wen, J. Du, X. Li, Y. Liu, J. Feng, Y. Xie, Y. Bai, H. Wang, and Y. Liu. 2018. Nitric oxide balances osteoblast and adipocyte lineage differentiation via the JNK/MAPK signaling pathway in periodontal ligament stem cells. Stem Cell Res. Ther. 9:118. https://doi.org/10.1186/s13287-018-0869-2.

Yin, H., L. Xu, and N. A. Porter. 2011. Free radical lipid peroxidation: Mechanisms and analysis. Chem. Rev. 111:5944-5972. https://doi .org/10.1021/cr200084z.

Yin, J., Z. Gao, Q. He, D. Zhou, Z. Guo, and J. Ye. 2009. Role of hypoxia in obesity-induced disorders of glucose and lipid metabolism in adipose tissue. Am. J. Physiol. Endocrinol. Metab. 296:E333E342. https://doi.org/10.1152/ajpendo.90760.2008.

Zachut, M. 2015. Defining the adipose tissue proteome of dairy cows to reveal biomarkers related to peripartum insulin resistance and metabolic status. J. Proteome Res. 14:2863-2871. https://doi.org/ 10.1021/acs.jproteome.5b00190.

Zachut, M., G. Kra, L. Livshitz, Y. Portnick, S. Yakoby, G. Friedlander, and Y. Levin. 2017a. Proteome dataset of subcutaneous adipose tissue obtained from late pregnant dairy cows during summer heat stress and winter seasons. Data Brief 12:535-239. https: //doi.org/10.1016/j.dib.2017.04.042.
Zachut, M., G. Kra, L. Livshitz, Y. Portnick, S. Yakoby, G. Friedlander, and Y. Levin. 2017b. Seasonal heat stress affects adipose tissue proteome toward enrichment of the Nrf2-mediated oxidative stress response in late-pregnant dairy cows. J. Proteomics 158:52-61. https://doi.org/10.1016/j.jprot.2017.02.011.

Zachut, M., G. Kra, U. Moallem, L. Livshitz, Y. Levin, S. Udi, A. Nemirovski, and J. Tam. 2018. Characterization of the endocannabinoid system in subcutaneous adipose tissue in periparturient dairy cows and its association to metabolic profiles. PLoS One 13:e0205996. https://doi.org/10.1371/journal.pone.0205996.

Zachut, M., G. Kra, N. Nemes-Navon, N. Ben-Aharon, U. Moallem, Y. Lavon, and S. Jacoby. 2020. Seasonal heat load is more potent than the degree of body weight loss in dysregulating immune function by reducing white blood cell populations and increasing inflammation in Holstein dairy cows. J. Dairy Sci. 103:10809-10822. https://doi.org/10.3168/jds.2020-18547.

Zhang, F., D. Li, Q. Wu, J. Sun, W. Guan, Y. Hou, Y. Zhu, and J. Wang. 2019. Prepartum body conditions affect insulin signaling pathways in postpartum adipose tissues in transition dairy cows J. Anim. Sci. Biotechnol. 10:38. https://doi.org/10.1186/s40104 $-019-0347-4$

Zhang, W., E. P. Mottillo, J. Zhao, A. Gartung, G. C. VanHecke, J. F. Lee, K. R. Maddipati, H. Xu, Y. H. Ahn, R. L. Proia, J. G. Granneman, and M. J. Lee. 2014. Adipocyte lipolysis-stimulated interleukin-6 production requires sphingosine kinase 1 activity. J. Biol. Chem. 289:32178-32185. https://doi.org/10.1074/jbc.M114 .601096.

Zhou, C., N. Zaman, Y. Li, D. B. Martinez-Arguelles, V. Papadopoulos, B. Zirkin, and K. Traore. 2019. Redox regulation of hormone sensitive lipase: Potential role in the mechanism of MEHP-induced stimulation of basal steroid synthesis in MA-10 Leydig cells. Reprod. Toxicol. 85:19-25. https://doi.org/10.1016/j.reprotox.2018 .12 .010 .

Zu, L., J. He, H. Jiang, C. Xu, S. Pu, and G. Xu. 2009. Bacterial endotoxin stimulates adipose lipolysis via toll-like receptor 4 and extracellular signal-regulated kinase pathway. J. Biol. Chem. 284:5915-5926. https://doi.org/10.1074/jbc.M807852200.

\section{ORCIDS}

Maya Zachut (ํ) https://orcid.org/0000-0002-9644-6028 G. Andres Contreras @ https://orcid.org/0000-0003-4969-2178 